\title{
Credibility and Cheap Talk of Securities Analysts: Theory and Evidence*
}

\author{
Jordi Blanes i Vidal ${ }^{\dagger}$ \\ London School of Economics \\ JOB MARKET PAPER \\ October 2003
}

\begin{abstract}
A bstract
This paper studies how investors react to public messages that may be optimistically biased. We first construct a communication game between an investor and a (possibly) biased securities analyst. We find an equilibrium characterised by the following properties: first, the investor reacts more to bad news than to good news, and second, the difference in this reaction is higher when the investor has a greater prior suspicion that the analyst is a biased type. We then use nonparametric techniques and a large database of earnings forecasts to test these predictions, and find that the evidence supports them. Lastly, we use our empirical strategy to discriminate between the causes for analysts' bias.

Keywords: Cheap Talk, Credibility, Securities Analysts, Stock Market Reaction

J EL Classification: C14 (Semiparametric and Nonparametric Methods), D82 (Asymmetric and Private Information), G14 (Information and Market Efficiency; Event Studies)
\end{abstract}

${ }^{*}$ The author would like to thank Oriana Bandiera, Heski Bar-Isaac, Clare Leaver, Oliver Linton, Felix Muennich, Andrew Patton, Hyun Shin, Julia Shvets, Michela Verardo and seminar participants at Bristol, LSE, Tilburg and Valencia for helpful comments and suggestions. Particular thanks are due to Andrea Prat and Marco Ottaviani. All errors are my own. I also thank First Call for making the $\mathrm{I} / \mathrm{B} / \mathrm{E} / \mathrm{S}$ database available for academic use.

${ }^{\dagger}$ London School of Economics, Houghton Street, London WC2A 2AE, United Kingdom Email Address: j.blanes@lse.ac.uk. 
Star analyst Henry Blodget "described the shares of excite@home, which he publicly rated as a short-term accumulate and long-term buy, as "such a piece of crap". Of InfoSpace, both a short- and a long-term buy, he claimed in private emails that the "stock is a powder keg"" The Economist [39].

\section{Introduction}

Securities analysts are often accused of trying to propagate enthusiasm about the companies they cover, irrespective of their personal opinions. The media regularly carries stories illustrating analysts' distorted incentives and how they lead to their unwarranted optimism. Regulators have also shown their concern through Regulation Fair Disclosure and other recent reforms aimed at reinforcing the separation between the research and corporate departments of big sell-side houses. At the core of these new regulations is the presumption that small investors need to be protected from unscrupulous analysts. On the other hand, big sophisticated investors -who account for the great majority of volume traded ${ }^{1}$ - are believed to be aware of analysts' potential conflicts of interest ${ }^{2}$. Efforts to protect small investors are undoubtedly praiseworthy. However, it is also important to consider the wider question of how investors as a whole react to analysts' public advice, when pondering analysts' influence on the financial markets.

Unfortunately the academic literature on analysts' earnings forecasts has largely avoided this question. The optimistic bias in analysts' forecasts has been the focus of a considerable body of work ${ }^{3}$, mostly studying its causes and evolution in time. However, the possibility that investors may not take these forecasts at face value has been consistently overlooked in these studies. This has clearly hindered our understanding of how information is transmitted and interpreted in the financial markets when the incentives of the parties involved diverge.

This paper fills this gap by explicitly studying the interaction between a rational investor and an analyst who may be optimistically biased. We show theoretically that uncertainty about the incentives of the analyst makes the investor assign different levels of credibility to different messages. This has two intuitive testable consequences: the investor reacts more to bad news than to good news, and this difference is larger when she has a higher prior suspicion that the analyst is a biased type. We then use nonparametric techniques to show that the stock market's reaction to analysts'

\footnotetext{
${ }^{1}$ For instance, the NYSE Research Department computed that in May 2000, institutional investors accounted for 64 percent of all order flow, broker-dealers for 27 percent, individual investors for 4 percent, floor-entered orders for 3 percent and the remaining 2 percent were unidentified (Badrinath and Wahal [6]) .

${ }^{2}$ See Boni and Womack [10], for survey-based evidence of this.

${ }^{3}$ See, for instance, Abarbanell and Lehavy [1], Brown [11], Chen and Jiang [12], Dechow, Hutton and Sloan [15], Gu and Wu [23], Lim [29], Lin and McNichols [30], McNichols and O'Brien [31], and Michaely and Womack [32].
} 
earnings forecasts is consistent with these predictions.

Our model is related to the literature of "cheap talk" started by Crawford and Sobel [14]. Although this theoretical literature has become increasingly popular in the last two decades, it has not been followed by a similar surge in studies testing its empirical implications. As a result very little is known about its predictive power. One of our major contributions is to combine a theoretical and empirical analysis in the field of strategic information transmission within a continuous space.

Model and Theoretical Results

In our model the investor is uncertain about the type of the analyst, whereas the analyst observes both his own type and the earnings that he expects the company to make. He then issues a forecast (i.e. a "message") that the investor must interpret and react to. The analyst may be either "honest", in which case he will truthfully report his information, or "biased", in which case he will strategically raise his message in order to induce the investor into believing that the situation is better than he knows it to be. The driving force of the model is the fact that the investor can use the forecast to update the likelihood that the analyst is biased rather than honest. Optimistic forecasts are assigned a lower probability of mirroring the true information (i.e. they are not "credible") and are strongly discounted.

We study equilibria where the action of the investor depends continuously on the analyst's message. In the most informative of such equilibria, the action function is strictly increasing and concave if the message is not too optimistic, and flat if the message exceeds a certain value. Using comparative statics we find that the slope of the action function is lower if the investor has a higher prior suspicion that the analyst is biased.

The strict concavity of the reaction function is caused by the interaction between the optimal strategies of both agents. Intuitively, because the analyst anticipates that optimistic forecasts are given less credibility, the more favourable his private information about the company is, the more he exaggerates. By doing this he only strengthens the investor's presumption that she should heavily discount optimistic forecasts. In equilibrium the forecast of a biased analyst increases with his private information in a convex way, and its converse (i.e. the reaction of the investor) increases with the forecast only in a concave way. A similar intuition is behind the lower reaction to forecasts by highly suspected analysts.

Empirical findings

We test these predictions using a large database of company earnings, analysts forecasts and the stock market's reaction to them. We first find that analysts are indeed biased, especially when they announce good news. For instance, when an average analyst announces an optimistic forecast of 10 cents above the consensus, actual earnings are, on average, only 2 cents higher. However if the analyst announces bad news of 10 cents below the consensus, actual earnings are lower, on average, by 13 cents. Using nonparametric techniques we find that the function relating expected earnings and forecasts is indeed concave, as predicted by our model. 
We show next that investors react more to pessimistic forecasts than to optimistic ones. When an analyst announces good news of 10 cents, the price on the shares of this company increases, on average, by $0.15 \%$ on the day on which the announcement was made. However, if he reports a bad news of 10 cents the price decreases by $0.7 \%$, more than 5 times higher in magnitude. In our sample the standard deviation of the daily return is $3.6 \%$, so $0.7 \%$ is an economically significant magnitude. We plot a nonparametric regression of the stock market reaction to analysts forecasts and find again a concave curve.

We then study the effect on investors' reaction of their prior suspicion that the analyst is biased. We conjecture that if an analyst has predicted above actual earnings in most of his forecasts in the past, investors will consider him very likely to be optimistically biased. We indeed find that when such analysts announce an optimistic forecast of 10 cents, the share price does not increase. However if the same forecast is announced by an analyst who has not issued too optimistic forecasts in the past, the share price reacts by a magnitude of $0.27 \%$. Again, this is economically significant.

Lastly, we discriminate amongst possible causes for analysts' bias. Our evidence is preliminary, but suggestive. We find the bias to be higher if the analyst is working for a smaller brokerage house and the company covered is bigger and followed by more analysts. We conjecture that the misalignment of incentives may be related to the "bargaining power" of the analyst versus the managers of the company studied.

\section{Outline}

The rest of the paper is organised as follows: Section 2 discusses related work. Section 3 outlines the model, and Section 4 derives the theoretical results, which are restated in the form of empirical predictions in Section 5. The data is presented in Section 6 and our main empirical results in Section 7. Section 8 discriminates among alternative causes for analysts' misaligned incentives. Section 9 briefly concludes. All the figures, tables and proofs are in the Appendix.

\section{Related work}

The theoretical contribution closest to ours is Morgan and Stocken [33]. These authors propose a continuous model with two types of strategic senders who differ on whether or not their preferences are aligned with those of the receiver's. They restrict their attention to a scenario where the state space is bounded. One of their equilibria allows the advisor with aligned preferences to credibly transmit his private information, if it is unfavourable enough. However, his information cannot be transmitted if it exceeds the sum of the lowest possible state value and the bias of the misaligned advisor. The reason is that the unbiased advisor can only convey information in the range of messages that he would never use if he was positively biased. The range of values where Morgan and Stocken's equilibrium applies is very limited in most 
real-life examples and strictly zero in an unbounded state space scenario ${ }^{4}$.

Ottaviani and Squintani [36] were the first to introduce a non-strategic agent in a Crawford and Sobel framework. They focus on the case of a non-strategic receiver and find an equilibrium where the action function is continuous in the message. They also find that this equilibrium is characterised by an ex ante biased action and by no loss of information due to strategic reasons. In this paper we complement their work by studying the case of a sender who may be non-strategic with some probability. Contrary to them, however, we find that some information is lost in equilibrium. Furthermore, our interest is in characterising the most efficient equilibrium, whereas Ottaviani and Squintani only show its existence.

The issue of credibility and cheap talk was previously studied by Sobel [38] and Benabou and Laroque [7]. However their binary-state repeated models are less related to our work.

On the empirical side the paper most related to ours is Michaely and Womack [32]. They study the stocks that, following an IPO, were positively recommended by underwriter and non-underwriter analysts. They show that the former perform poorly in comparison to the latter, and interpret this as evidence that underwriter analysts are positively biased in their stock recommendations. Furthermore, they find some weak evidence that the market may be aware of this bias, and therefore reacts less to a "buy" recommendation if issued by an underwriter analyst ${ }^{5}$. We improve on Michaely and Womack on several grounds. By focusing on earnings forecasts (a continuous variable) rather than on stock recommendations (a discrete variable), we are able to study the curvature of the stock's market reaction, and provide much sharper evidence of the way in which the market discounts the bias. Furthermore, the use of a theoretical model allows us to enrich the set of testable predictions and to consider an alternative hypothesis. Lastly, our predicted variable is not affected by the recommendation of the analyst, and therefore our test, unlike Michaely and Womack's, does not suffer from endogeneity problems.

\section{Credibility in a cheap talk model}

An investor (she) is interested in acquiring shares of a certain company if that is profitable. Among the various variables that affect such profitability, the investor pays attention to its future earnings. At a given moment in time, the market holds an underlying consensus, $c$, about those future earnings and such consensus is incorporated in the price of the shares. The investor responds to news related to the company, buying when the news is favourable in relation to the consensus and selling otherwise.

\footnotetext{
${ }^{4}$ Clearly this is the realistic scenario in our application of earnings per share. It is also realistic in Morgan and Stocken's example, whose focus is the future share price of the company.

${ }^{5}$ The difference between the reactions to the two types of analysts is only significant at the $10 \%$ level.
} 


\section{Information Structure}

Although the investor is interested in learning more about the company, she has no independent means of obtaining such information, either due to limited attention (there may be many alternative investment opportunities to consider) or lack of the expertise required to understand its accounts or strategy. A securities analyst (he) has this information. He uses it, in conjunction with $c$, to compute an optimal (private) guess, $g$, about future earnings. Define $x=g-c$ as the news above or below consensus arising from the private information of the analyst. We assume that $x$ is distributed normally with zero mean, $x \sim N\left(0, \sigma^{2}\right)$.

Preferences

The investor's gain from learning $x$ arises from the opportunity to rebalance her investment portfolio due to the new information. Define $a$ as the action of buying or selling shares, where strictly positive (negative) values of $a$ account for buying (selling) shares, and $a=0$ accounts for doing nothing. With each piece of news and action is associated a benefit, $U^{I}=U^{I}(a, x)$. We simplify the portfolio decision by assuming that the utility of the investor reaches a unique maximum for $a^{I}=x$ and is:

$$
U^{I}(a, x)=-(a-x)^{2}
$$

This function can be interpreted as the utility loss suffered by the investor when she fails to adjust her portfolio efficiently in the light of new existing information.

The central conflict of the model arises because the preferences of the investor and the analyst may not be perfectly aligned. In particular, we assume that the analyst may prefer the investor to take a higher action than is optimal for her, $a^{A}=$ $x+b>x=a^{I}$, where $b>0$ is the degree of dissonance between the preferences of both agents. Assume that $q$ is the prior probability that the analyst is biased. There are different ways of deriving such conflict of interest from the preferences of the analyst. We follow Morgan and Stocken [33] and assume that the objective function of the biased analyst consists of two elements: a benefit associated with inflating the investor's action and a cost associated with poor performance caused by the distortion of the information revealed to the investor.

$$
U^{A}(a, x, b)=2 b a-(a-x)^{2}
$$

We also allow for the possibility of the analyst being honest and non-strategic and therefore reporting his information truthfully. This assumption is also used by Ottaviani and Squintani [36] and by Benabou and Laroque [7]. The justifications for this assumption can be behavioural (an analyst adhering to a code of ethics by which distorting information is considered immoral) or in terms of payoff uncertainty. In reality, an analyst who misrepresents his private information runs some risk of being discovered and fined huge penalties. For instance, when the above mentioned Henry 
Blodget, was discovered to hold different views in his private e-mails from the ones that he maintained in public, he was fined $\$ 4 \mathrm{~m}$ and barred from the securities industry for life ${ }^{6}$. Our assumption of non-strategic honesty could therefore apply to analysts who are very risk averse or who estimate the chances of being caught lying as very high. We believe, however, that allowing for a strategic analyst with aligned incentives who cared about being perceived as not biased would not qualitatively alter our theoretical results.

\section{Information Transmission and Contracts}

In line with the cheap talk literature, we adopt the view that an investor has no means of inducing truthful revelation through a contract. The analyst can, however, issue a message $m$ to influence the investor's belief over his privately observed $x$. The message takes the form of a forecast $f$, where $m=f-c$. An honest analyst always truthfully announces $m=x$. A biased analyst, by contrast, follows a message

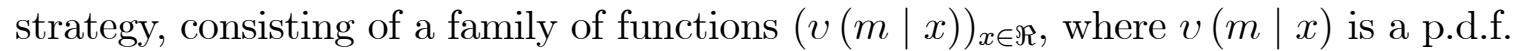
of $m$ given $x$. If the analyst follows a pure strategy over some range of the state space, $\left[x_{1}, x_{2}\right]$, then $v(m \mid x)$ is degenerate in this range and can be represented by the function $\mu: x \rightarrow m$.

Timing

The timing is as follows: (i) The analyst learns his type, honest or biased (ii) The analyst learns $x$ and issues a message $m$ (iii) The investor observes $m$ and adopts an action $a$ (iv) The payoffs of both agents are realised.

\section{Equilibrium concept}

We study Perfect Bayesian Equlibria (PBE), where investor's beliefs are formed using Bayes' rule and, given those beliefs, the biased analyst maximises his payoff.

\section{Analysis}

In the model outlined in Section 3, there is a misalignment of incentives that may create obstacles to the transmission of information. It is therefore important to know whether, under the different equilibria of this model, an analyst of a particular type can successfully induce higher actions when he observes a higher state of the world. Define $A_{i}^{j}(x)$ as the action that occurs under a particular equilibrium of the model, $j$, when an analyst of type $i$ observes a state of the world $x$. Define $a^{j}(m)$ as the action that occurs under equilibrium $j$ when a message $m$ is issued.

We restrict our attention to equilibria where $A_{i}^{j}(x)$ is a continuous function (i.e. the action does not "jump around" when the state of the world is slightly higher or lower). We then focus our analysis on the responsiveness of the action to the state of the world under the different equilibria.

\footnotetext{
${ }^{6}$ In a similar scandal, another analyst employed by Citigroup was fined $\$ 15 \mathrm{~m}$ and also barred from the industry.
} 
Definition 1 We define a continuous equilibrium as an equilibrium where the function $A_{i}^{j}(x)$ is continuous. Consider two continuous equilibrium functions, $A_{i}^{J}(x)$ and $A_{i}^{K}(x)$, and assume that they are strictly increasing in the sets of state values $X_{i}^{J}$ $\subseteq R$ and $X_{i}^{K} \subseteq R$ respectively.

1. We define equilibrium $J$ as being more responsive than equilibrium $K$ if $X_{i}^{K} \subset$ $X_{i}^{J} \forall i$.

2. We define equilibrium $J$ as the most responsive continuous equilibrium if every other continuous equilibrium $j$ of the model has a corresponding $X_{i}^{j}$ such that $X_{i}^{j} \subset X_{i}^{J} \forall i$.

3. We define equilibrium $J$ as being fully-responsive if $X_{i}^{J}=R \forall i$.

Intuitively, high responsiveness corresponds to a situation when a lot of information is being credibly transmitted by the analyst (i.e. the investor is responding to higher messages by taking higher actions).

Our aim in this section is to characterise the most responsive equilibrium. To do this, we solve the model by backwards induction and apply our equilibrium concept. We start by finding the optimal reaction of an investor to a message, and then solve for the optimal strategy of a biased analyst.

\subsection{The investor's problem}

As will be shown below, a biased analyst strategically raises his message above his private information to induce higher actions by the investor. A rational investor will therefore be cautious about following the message literally. To the extent that $m$ is informative about $x$, however, it should not be discarded. Define $v(m \mid x)$ as the mixed strategy that the investor believes that a biased analyst is following upon observing $x$, with $\int v(m \mid x) d m=1$, and $\mu(x)$ as the equivalent in pure strategies. Define also $\phi($.$) and \Phi($.$) as the normal density function and the normal distribution$ function respectively. The optimal reaction of the investor can be written as the solution to the problem:

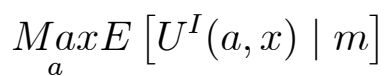

Lemma 2 The optimal reaction of an investor to a message $m$ is given by:

$$
a=E[x \mid m]=\frac{(1-q) m \phi(m)+q \int_{-\infty}^{\infty} x v(m \mid x) \phi(x) d x}{(1-q) \phi(m)+q \int_{-\infty}^{\infty} v(m \mid x) \phi(x) d x}
$$

If the message is believed to having been issued using a pure strategy, the optimal reaction is given by:

$$
a=E[x \mid m]=\frac{(1-q) m \phi(m)+q \mu^{-1}(m) \phi\left(\mu^{-1}(m)\right)}{(1-q) \phi(m)+q \phi\left(\mu^{-1}(m)\right)}
$$


The intuition of $(3)$ is the following. The investor is uncertain about two things: the information of the analyst, $x$, and his type, "honest" or "biased". If the investor knew with certainty that the analyst is honest, her optimal action would be $a=m$. Conversely, if she knew that the analyst is a biased type, it would be optimal to make $a=\mu^{-1}(m)$. The weight that the investor gives to $m$ ("following literally") over $\mu^{-1}(m)$ ("undoing the bias") can therefore be regarded as the "credibility" that the message receives. (3) states that this credibility is equal to the Bayesian posterior probability of the message having been created by an hol(or)(h)n 
the proof of Proposition 3 (see Appendix) shows that this is impossible. The reason is that, for a sufficiently high value of $x$, a value of $m$ that meets $E[x \mid m]-x-b=0$ cannot be found.

To understand the intuition, assume that the message is sent using a pure strategy and note that, in this case, $E[x \mid m]-x-b=0$ can be rewritten as:

$$
F(m, x)=m-x-b\left(1+\frac{q \phi(x)}{(1-q) \phi(m)}\right)=0
$$

A fully-responsive equilibrium requires the message to be always higher than the information of the analyst by an amount at least equal to the bias. Moreover, when $x$ is higher the credibility of the corresponding message is lower (note that $\left.\frac{d}{d x}[q \phi(x) /(1-q) \phi(x+b)]>0\right)$ and the "wedge" between $m$ and $x$ has to be higher to meet condition (5). In fact it turns out that, when $x$ is high enough, credibility is so low that it becomes impossible to find a message that will induce a biased action from the investor.

\subsubsection{The most responsive equilibrium}

After ruling out fully-responsive equilibria, we characterise the continuous equilibrium where more information is transmitted to the investor.

Proposition 4 The most responsive continuous equilibrium meets the following conditions:

1. There exists a cutoff value, $x^{*}$, that divides the state space in two sections. There exists a cutoff value, $m^{*}$, that divides the message space in two sections. $m^{*}$ is a solution to the equation $F\left(m, x^{*}\right)=0$.

2. When the biased analyst observes $x \leq x^{*}$, he issues his message in pure strategies using a function $m^{1}(x)$ that is strictly increasing. When the message is $m \leq m^{*}$ the action function, $a(m)$, is strictly increasing and satisfies:
(a) $\frac{\partial^{2} a}{\partial m^{2}}<0$
(b) $\frac{\partial^{2} a}{\partial m \partial q}<0$

3. :

(a) When the message is $m>m^{*}$, the investor takes an action $a^{*}$ determined by the equation:

$$
a^{*}=\frac{q \phi\left(x^{*}\right)+(1-q) \phi\left(m^{*}\right)}{q\left(1-\Phi\left(x^{*}\right)\right)+(1-q)\left(1-\Phi\left(m^{*}\right)\right)}
$$


(b) When the biased analyst observes a value $x>x^{*}$ his message is chosen in mixed strategies $v(m \mid x)$ so as to make, $\forall m$ :

$$
\frac{(1-q) m \phi(m)+q \int_{x^{*}}^{\infty} x v(m \mid x) \phi(x) d x}{(1-q) \phi(m)+q \int_{x^{*}}^{\infty} v(m \mid x) \phi(x) d x}=a^{*}
$$

4. A biased analyst that observes $x^{*}$ is indifferent between issuing a message in the responsive or the non-responsive parts of the equilibrium.

$$
a^{*}=\frac{q \phi\left(x^{*}\right) x^{*}+(1-q) \phi\left(m^{*}\right) m^{*}}{q \phi\left(x^{*}\right)+(1-q) \phi\left(m^{*}\right)}
$$

The action function in the most responsive equilibrium is plotted in Figure $\mathrm{C}$ (see Appendix). Note that the action function is increasing and concave when the message is below certain value, $m^{*}$, and flat if the message is too optimistic.

Intuition of the equilibrium

To understand the logic behind the equilibrium, consider first its responsive part. Figure A plots the equilibrium message function of the biased analyst, $m^{1}(x)$, when the state of the world is below $x^{*}$. Note that it is a convex function (see Lemma 6 in the Appendix for a formal result). The intuition is the following. If $x$ is higher, the analyst has also to make the message higher if he is to induce an inflated action from the investor. In fact, he has to make $m$ higher by a larger amount than the increase in $x$, in order to compensate for the loss of credibility when he conveys more optimism in his message. Therefore, when $x$ is higher, $m$ and $x$ are further apart in equilibrium.

How does the slope of the message function depend on $x$ ? If $x$ increases from an already high position, the analyst is more affected by subsequent losses of credibility (i.e. a decrease of $[q \phi(x) /(1-q) \phi(m)]$ reduces the action by more because $m$ and $x$ are further apart). As a result, as $x$ increases the analyst has to exaggerate increasingly more to maintain a "wedge" between the investor's optimal average of $x$ and $m$ and the true state of the world $x$. Hence, the convexity of the message function.

However, the equilibrium action function is the reverse of the message function (note that, in the responsive part of the equilibrium, $a=\mu^{-1}(m)+b$, where $\mu=m^{1}(x)$ is the equilibrium message function). The strict concavity in the responsive part (see Figure $\mathrm{C}$ when $m \leq m^{*}$ ) is the reverse of the strict convexity of the message function. Intuitively, because the analyst exaggerates increasingly as $x$ becomes higher, a rational investor discounts increasingly as the message becomes more optimistic.

A similar intuition lies behind Part 2b of Proposition 4. When $q$ is higher, the weight that the investor assigns to the analyst telling the truth becomes lower. Consequently in equilibrium $m$ and $x$ are further apart, at any state of $x$, if the biased analyst is reaching his bliss point. That makes the analyst more seriously affected by the loss of credibility, and more prone to exaggeration, when $x$ becomes higher. The 
message function has therefore a higher slope if the exogenous parameter $q$ is higher (see Figure B). Conversely, the action function has a lower slope in its responsive part (see Figure D), as higher strategic optimism by an analyst with a higher $q$ is matched by stronger discounting of the messages produced by such analyst.

Consider now the logic of the non-responsive section of the equilibrium. Because all messages are treated equally, the investor's rationality requires the action to be the average of the possible states observed by any analyst that would issue a message above $m^{*}$. Part 3a of Proposition 4 comes simply from rearranging this condition. We do not characterise explicitly the (family of) message functions in the non-responsive section $^{7}$. We know, however, that a valid message function must leave the investor completely uninformed about where the state of the world lies (obviously, the investor knows that $x$ lies in the interval $\left(x^{*}, \infty\right)$, but not where in the interval). Because the honest analyst always reports the truth, the combined message can only be uninformative if the biased analyst "hides" this information by adopting a message function that makes the expected state, conditional on the message, always equal to $a^{*}$. Equation (7) displays this condition.

Lastly, Part 4 states that the action function must be continuous at the intersection between the responsive and the non-responsive section.

Other equilibria

There are two other continuous equilibria in this game. We describe them in the proof of Proposition 4. One of them is the standard non-responsive equilibrium, displayed in Figure E. In this equilibrium, the message of the analyst is completely uninformative, and the action of the investor coincides with the unconditional expectation of $x$. The other equilibrium is identical to the most responsive equilibrium of Proposition 4 except for a "flat" section in the left tail of the message space (see Figure F). From the figure it is immediate to conclude that both equilibria are less responsive than the one displayed in Figure C.

\subsection{Existence}

The existence of the most responsive equilibrium is not guaranteed for every possible set of the exogenous parameter values $\left(b, q, \sigma^{2}\right)$. There are two reasons for this. Firstly, the system of equations (6) and (8), which together determine the point $\left(x^{*}, m^{*}\right)$ which separates the space into two sections, may not have a solution. Proposition 3 states that (5), and therefore (8), are not defined for every possible value of $x$. As a result the intersection with the curve (6) is not guaranteed, and an equilibrium may not exist.

The second reason is with respect to the family of message functions in the flat section of the state space. Observe the left hand side of condition (7). The honest

\footnotetext{
${ }^{7}$ This does not imply a loss of predictions because empirically we only observe $E[x \mid m]$ and $m$, and not $x$. Therefore it is not possible to test any predictions on the message function and our empirical efforts will be directed to the estimation of the action function.
} 
analyst, who is part of the game with probability $(1-q)$, issues messages in this section of the equilibrium with a probability $\left[1-\Phi\left(m^{*}\right)\right]$. Such messages have to be uninformative to the investor (i.e. they must be hidden) for the equilibrium to exist. This is only possible if the biased analyst, who exists with probability $(1-q)$, issues the correct messages when he observes a state higher than $x^{*}$, something that happens with probability $\left[1-\Phi\left(x^{*}\right)\right]$. It seems clear that as $q$ tends to $0,(7)$ cannot hold for every message $m>m^{*}$. We posit that a necessary and sufficient condition for the existence of a family of functions $v(m \mid x)$ that make $(7)$ hold is that a state observed by a biased analyst occurs at least as often as a state observed by an honest analyst $\left((1-q)\left[1-\Phi\left(m^{*}\right.\right.\right.$ 
investors, $(m=f-c)$, but not his private information $(x=g-c)$. It is impossible to establish with certainty whether a particular analyst has strategically raised his forecast, as we cannot directly compare $x$ with $m$. By using actual earnings per share (e) we can, however, study statistically whether analysts are likely to be strategically raising their forecasts. The difference between actual earnings and the consensus at a particular moment in time is, by definition, an unbiased expectation of the private information held by an analyst at that moment in time: $(e-c)=E[g]-c=E[x]$. The theoretical relation between $E[x]$ and $m$ can then be captured empirically by the relation between actual earnings and forecasts.

$$
E[x]=(e-c)=\varphi(f-c, q)+\varepsilon
$$

If all analysts report their information truthfully $(m=x)$ we will find ${ }^{8}$ that $\frac{\partial(e-c)}{\partial(f-c)}=1, \frac{\partial^{2}(e-c)}{\partial(f-c)^{2}}=0$ and $\frac{\partial^{2}(e-c)}{\partial(f-c) \partial q}=0$. By contrast, a finding that $\frac{\partial(e-c)}{\partial(f-c)}<1$, $\frac{\partial^{2}(e-c)}{\partial(f-c)^{2}}<0$ and $\frac{\partial^{2}(e-c)}{\partial(f-c) \partial q}<0$ would provide support for our theoretical model.

We proxy $q$ for a particular analyst in a certain period $t$ by the percentage of times that this analyst has forecasted above the actual value $((e-c)-(f-c)>0)$ in the periods previous to $t$. Under the null hypothesis of truthtelling, analysts will incur in a high percentage of positive (optimistic) errors only by chance. Consequently a high value of the proxy for $q$ should be uninformative about his present message strategy. In our model, however, past positive errors are indicative of the analyst being a biased type and are therefore informative about his present behaviour.

Equation (9) draws a relation between a forecast and an optimal expectation of earnings as constructed by the econometrician. However, it does not shed light on whether real investors behave in a manner consistent with the theoretical model ${ }^{9}$. To study this, we construct an event study using the change in the price of the shares of a company around the date on which a forecast on this company was made. To see the logic of the test, take $r$ as the return around the forecast date, $r=(\Delta P / P)$. The shares of a company increase in price when good news about its earnings are believed by investors. Conversely, the daily return will be negative when bad news arrives to the market. We can study therefore the following relationship:

$$
r=\pi(f-c, q)+\eta
$$

If all analysts are truthful in their forecasts (and investors know it), we will find that $\frac{\partial^{2} r}{\partial(f-c)^{2}}=0$ and $\frac{\partial^{2} r}{\partial(f-c) \partial q}=0$. By contrast the finding that $\frac{\partial^{2} r}{\partial(f-c)^{2}}<0$ and $\frac{\partial^{2} r}{\partial(f-c) \partial q}<0$ would provide support for our theoretical model.

\footnotetext{
${ }^{8}$ These predictions also hold even if the analyst is not perfectly informed about actual earnings, although in such case the goodness of fit of any estimation will be lower.

${ }^{9}$ The fact that the action equals the ex post expected state of the world is not a general result, but a direct consequence of using a quadratic loss function centred around $x$. In the real world, there are many reasons why $a$ and $E[x \mid m]$ differ. For example the investor may face non-linear transaction costs, or his valuation of the shares of the company may not increase linearly with its earnings. For this reason it is important to study the actions of investors separately.
} 


\subsection{Cognitive biases and Naive Investors}

Essential to our theoretical results is the assumption of strategic behaviour for both the biased analyst and the investor. In fact, our results do not hold if we drop the assumption of rationality from any of them. To see this, we first study the case of analysts suffering from "behavioural optimism", and then comment on the case of "naive investors".

Khaneman and Lovallo [25] have suggested that some analysts view the companies that they are covering in a unique narrow frame (the same way as parents view their children as better than their neighbours'). They are unable to accept the fact that their companies may do badly, and therefore experience optimistic cognitive biases on them. There are different ways to study the action function under what Khanneman and Lovallo term "the insider's view". In our framework, we could assume that all analysts suffer from a cognitive bias $b$ on the company that they follow. In this case the optimal action of investors would be to just subtract $b$ from the message, $a=m-b$ (see Figure $\mathrm{G})$.

Alternatively, assume now that some analysts are unbiased $(m=x)$ whereas others suffer from cognitive bias $(m=x+b)$. The type of the analyst is unknown to the investor. The difference of this scenario with respect to our model in Section 3 lies only in the assumption that the biased analyst is non-strategic here. The optimal reaction of an investor to a message $m$ in this case is:

$$
a=E[x \mid m]=\frac{(1-q) m \phi(m)+q(m-b) \phi(m-b)}{(1-q) \phi(m)+q \phi(m-b)}
$$

The plot of (11) in Figure H (details available upon request) shows that the action function is concave along some range and then convex. A non-strategic analyst does not anticipate the investor's discounting of more optimistic messages and therefore does not raise his forecast more when he observes a higher $x$. As a result, a rational investor never discounts from the message a magnitude higher than $b$. When the message is very optimistic, an amount very close to $b$ has already been discounted, and the slope of the reaction function is therefore close to one.

Consider now the case of a strategic and biased analyst and a naive investor. In this case the action of the investor and the econometrician's optimal estimate of earnings do not coincide $(a \neq E[x \mid m])$. As Figure I shows, a naive investor takes the message at face value $(a=m)$. In such case it suffices for a biased analyst to add a constant bias to his message to reach his bliss point. Consequently, the optimal estimate of earnings has the same shape as in the case of the possibly biased non-rational analyst. We display this case in Figure J. 


\section{Data}

Quarterly earnings per share forecasts and earnings are taken from the I/B/E/S Detail Database ${ }^{10}$. In order to reduce heteroskedasticity, we eliminate forecasts for firms with share prices below $\$ 5$ or market capitalisations below $\$ 100$ million (both in 2002 CPI-deflated dollars) and we scale forecasts and earnings by the stock price 10 days before the forecast date. We further trim the $1 \%$ extreme values of the test variables to avoid concerns that the results are driven by outliers. Our results are not, however, sensitive to the choice of outlier rule.

The unit of analysis is an analyst-firm pair. The reason for this is that an analyst may be biased with respect to one firm but not with respect to another. In the future we will often use the term "analyst" for an analyst-firm pair whenever no confusion is caused.

We are conducting an event study, so it is important to establish with some accuracy the date on which a forecast was made. I/B/E/S has reported this date with increasing precision over time, with a big improvement occurring at the beginning of the nineties, when the data-entering system was switched from manual into electronic. From 1992 almost all analyst enter their forecasts directly into the system, usually within 24 hours of providing them to clients. We limit the sample to the period 1993-2001.

We compute the consensus $c$ as the average of all forecasts made on the last day on which a forecast occurred. Because forecasts on a specific day incorporate information contained in previous forecasts, we believe that this measure represents the best possible estimation of the prevailing consensus. However our results remain unchanged even when we use alternative measures, like the average of the last three forecasts or a weighted average of all prevailing forecasts. Our test variables are Earnings $=E A R N I N G S-C O N S E N S U S=(e-c)$ and Forecast $=$ FORECAST - CONSENSUS $=(f-c)$. Henceforth in the paper we will refer to earnings and forecasts as the variables net of the consensus, and to gross earnings and gross forecast as the variables before the consensus is subtracted.

We compute a proxy for $q$ using the past information on the analyst-firm pair. We first construct a variable $d$ that equals 1 if a forecast is above actual earnings and 0 if it is equal to or below actual earnings. For every analyst-firm pair $s^{\text {th }}$ forecast, we compute a weighted average of $d$ from its first forecast to the forecast $s-1$. We use an inverse-weighting scheme to assign higher weights to more recent forecasts. If a forecast $l$ has been issued $h_{l}$ quarters before forecast $s$, the inverse weighting

\footnotetext{
${ }^{10} \mathrm{I} / \mathrm{B} / \mathrm{E} / \mathrm{S}$ has several advantages with respect to other databases. It is free of survivorship bias and (unlike Zacks) it comprises the great majority of public forecasts. Furthermore, unlike actuals from others sources like COMPUSTAT, I/B/E/S actual earnings are recorded on the same basis as I/B/E/S forecasts. According to Abarbanell and Lehavy [2] significant changes were made in the period 1989-1991 and in 1995 to systematically redefine reported earnings in order to improve its quality. Although we include in our sample some years previous to the 1995, all our results remain unchanged when we restrict the sample to the period 1996-2002.
} 
assigns weight $\omega_{l}=\left(1 / h_{l}\right)\left(\sum_{k=1}^{s-1}\left(1 / h_{k}\right)\right)$ to the value $d_{l}$ and our proxy for $q$ becomes Prior $_{i s}=\sum_{l=1}^{s-1} \omega_{i l} d_{i l}$. The inverse-weighting scheme accounts for two possible effects: a recency effect (investors remember better more recent forecast errors) and changing bias over time (more recent forecasts are more indicative of the existence of a bias in the present than forecasts in the distant past).

Lastly, we use CRSP data to assign a market reaction to every forecast. We compute investor's reaction as the abnormal return (i.e. the firm's raw return less the value-weighted market return) on the shares of the company on which a forecast was made, around the forecast date (all our main results remain unchanged when we use a two-day or a three-day window around the forecast date). Return $n_{i t}=$ $\frac{P_{i t}-P_{i t-1}}{P_{i t-1}}-\frac{M P_{i t}-M P_{i t-1}}{M P_{i t-1}}$, where $P$ is the share price of the company and $M P$ is the value-weighted average price of the market.

The sample we use contains 1,178,425 forecasts, covering 7,274 analysts, 7,236 firms and 526 brokerage houses over a period of 10 years. The number of firm-analyst pairs is 105,698 and the number of firm-quarter combinations is 110,137 . Table 1 reports summary statistics for the major variables used in the empirical analysis.

\section{R esults}

\subsection{Nonparametric results}

In this section we do not impose any parametric form on the estimation of the conditional means of earnings and returns:

$$
\begin{gathered}
\text { Earnings } \left._{i t}=\varphi \text { (Forecast }_{i t}, \text { Prior }_{i t}\right)+\varepsilon_{i t} \\
\text { Return }_{i t}=\pi\left(\text { Forecast }_{i t}, \text { Prior }_{i t}\right)+\eta_{i t}
\end{gathered}
$$

\subsubsection{Pooled Regressions}

We pool initially all analysts together. Figures K and L display the estimated relation between earnings, returns and forecasts. We use a nonparametric regression with a normal kernel, optimal bandwidth and 50 grid points. Both figures show that the estimated curves are concave and therefore support our model against any of the alternative hypotheses discussed in Section 5.1. Figure K also casts doubts over empirical efforts, common in the literature, based on the assumption that the relationship between earnings and forecasts is linear (see, for example, Zitzewitz [42]).

We interpret the concavity of the earnings function as evidence that analysts are positively biased specially when they make optimistic forecasts. We interpret Figure $\mathrm{L}$ as evidence that investors are aware of this fact, and interpret optimistic (but not pessimistic) forecasts with scepticism. 
Given the big sample size, the confidence intervals are very close to the estimated conditional means, specially for the (less noisy) earnings function.

Similar conclusions are reached by less sophisticated nonparametric strategies, like sorting the data into 100 groups according to the right-hand side variable and plotting the means of Earnings and Return against the mean of Forecast for each group.

Note lastly that the slope of the earnings function is slightly higher than 1 for pessimistic forecasts, a finding that is not consistent with our theoretical predictions. Although this is a potentially interesting question, we believe that it does not invalidate the relevance of our model.

In order to understand the economic magnitude of our findings, consider the example of a firm with a share price of $\$ 40$ and an underlying consensus about earnings in the following quarter of 40 cents per share. Assume that an average analyst makes a forecast of $0^{11}$. Figure $\mathrm{K}$ shows that the optimal expectation of earnings is slightly below 0 ; we find from the output of the nonparametric estimation that expected earnings are in fact, -0.7 cents (the optimal expectation of gross earnings is therefore 39.3 cents per share).

Assume now that the analyst makes a forecast of 10 cents, a very optimistic forecast (a forecast of 10 cents is approximately in the 90th percentile of the forecast distribution). We find that expected earnings conditional on such forecast are 1.3 cents, that is, only 2 cents higher than if the forecast is 0 .

Would a pessimistic forecast of equal magnitude have a similar absolute effect on expected earnings? Figure K shows that it would not. Quantitatively, expected earnings conditional on a forecast of -10 are -13.6 cents. We conclude that the magnitudes are significant: expected earnings change 6.5 times more if a forecast of 10 cents, in absolute value, is optimistic rather than pessimistic.

More importantly, do investors react differently to optimistic and pessimistic forecasts? The concavity of the curve in Figure L shows that they do. The standard deviation of the daily return in our sample is $3.6 \%$. Using the results of the nonparametric regression we find that the price of the shares of a company increases by only $0.15 \%$ when an analyst makes an optimistic forecast of 10 cents on a certain day. However, they decrease by an average of $0.7 \%$, (a magnitude more than 5 times higher, and around $20 \%$ of the daily return standard deviation) if the forecast is of the same absolute value but negative sign. The magnitudes are also economically significant.

\footnotetext{
${ }^{11}$ Remember that in this paper we have defined forecasts and earnings as net of the consensus. A (net) forecast of 0 therefore implies a gross forecast equal to the consensus, that is 40 cents per share.
} 


\subsubsection{R egressions by different values of Prior}

In this subsection we study the effect of the prior probability that the analyst is biased on the shape of the earnings and return functions. We rank the observations in the sample according to the variable Prior and split the sample into five quintiles. Higher (lower) quintiles refer to analysts that have predicted very often above (below) actual earnings.

We run nonparametric regressions separately for each quintile and plot them together in Figures M and N. Figure M shows that optimistic forecasts imply higher earnings only if they are announced by an analyst who has not predicted too optimistically in the past. Indeed the estimated functions for the first two quintiles are reasonably linear and close to the 45-degree line. On the other hand, optimistic forecasts announced by analysts with high values of Prior are strongly biased and not related to higher earnings. The bias is however much lower when such analysts make pessimistic forecasts. Indeed we find that the conditional mean functions for the three higher quintiles are strongly concave curves ${ }^{12}$.

Figure $\mathrm{N}$ displays the reaction of investors to the announcements made by different types of analysts. Importantly, investors react equally to any pessimistic forecast, regardless of who made it (note that the curves for different quintiles intersect if the news are pessimistic). However, investors react to an optimistic forecast by driving the price of the shares up only if that forecast is made by an analyst in a low quintile.

The difference in the reaction to optimistic news announced by different analysts is also economically significant. Assume for instance that a forecast of 10 cents is announced by an analyst in the first quintile. Using the output of the nonparametric estimations we find that expected earnings are 6.8 cents higher, and the share price increases by $0.27 \%$ (almost twice the reaction to an average analyst, and $7.5 \%$ of the daily return standard deviation). However, if the analyst announcing a forecast of 10 cents belongs to the highest quintile, expected earnings are actually lower (by 2 cents) and the share price changes by just $0.02 \%$ on average.

\subsection{Parametric Results}

In this section we complement the results above with the estimation of parametric nonlinear versions of (12) and (13). This allows us to introduce controls on the estimation and to account for intra-cluster serial correlation on the errors, a potentially serious problem.

\footnotetext{
${ }^{12}$ Note again that our theoretical model is not a perfect predictor of the pessimistic part of the earnings function. In particular, our model predicts the earnings function for each quintile to coincide with the 45 degree line (see Figure $\mathrm{C}$ above). We find however substantial deviations from the 45-degree line as well as from each other in our estimations.
} 


\subsubsection{Pooled Regressions}

We first study the concavity of our earnings and return functions for the average analyst:

$$
\begin{gathered}
\text { Earnings }_{i t}=\alpha+\alpha_{0} \text { Forecast }_{i t}+\alpha_{1}{\text { For } S q_{i t}}+\xi_{i t} \\
\text { Return }_{i t}=\beta+\beta_{0} \text { Forecast }_{i t}+\beta_{1} \text { For S }_{i t}+\beta_{2} \text { LReturn }_{i t}+\nu_{i t}
\end{gathered}
$$

, where For $S q$ accounts for Forecast Squared.

Because the return function is essentially an event study, it is important to ensure that we are capturing the reaction of investors to an individual forecast rather than to other contemporaneous firm-specific events that may affect their valuation of the firm. We add the one-day lagged abnormal return, LReturn, to the regression to control for this possibility. The public forecasts of securities analysts cannot react as quickly as the market to a firm-specific event, since analysts have to communicate their forecasts to their private clients at least some hours before releasing them publicly to the I/B/E/S system. As a result, introducing the lagged return should control for the effects of any event that influences the share price and also induces a revision of the firm's earnings forecast(in unreported regressions we ensure that adding up to five lags does not affect our results). We also include year and quarter dummies.

We estimate (14) and (15) by Least Squares and Analyst ${ }^{13}$ Fixed Effects. The $t$ statistics are constructed using cluster-adjusted standard errors, with all forecasts for the same firm-quarter grouped in one cluster. Cluster-adjusted standard errors guarantee consistency against arbitrary intra-cluster error correlation as well as arbitrary forms of heteroskedasticity across the whole sample. In our sample cluster-adjusted firm-quarter standard errors are much larger than GLS or OLS standard errors, and very similar to errors obtained by grouping forecasts by firm or by analyst. Thus we regard them as conservative estimates.

We also report the results of median regressions. Because very often financial data have very fat tails, it is important to ensure that our results are robust to outlying observations. Median regressions are more robust to outliers because they minimise the sum of absolute deviations, rather than the sum of squared deviations.

The results of the pooled parametric regressions are displayed in Table 2. The coefficients on Forecast and For $S q$ are positive and negative, respectively, across all regressions, confirming the existence of a concave relationship between our test variables. The $t$ statistics are all significant at the $1 \%$ level. Note that the introduction of fixed effects does not alter significantly the magnitude of the coefficients. The median regression of the return function, however, produces estimates that are much lower in value than the least squares estimation (0.19 versus 0.58). Although the coefficients are still significant, this seems to support our belief that observations at the tails of the distribution may have a disproportionate effect on our results.

\footnotetext{
${ }^{13}$ As we mentioned earlier throughout the paper we refer to an analyst-firm pair as an "analyst".
} 


\subsubsection{Regressions by different values of Prior}

In this subsection we interact Forecast and For $S q$ with the prior belief that the analyst is biased. We also allow for different intercepts by including both the variable Prior and its square, $\operatorname{Pr} S q$.

In the return function we introduce further controls to ensure that we are isolating the reaction of the market to individual forecasts. Because analysts sometimes release forecasts for the same firm on the same day, we control for the average forecast of the other analysts who made an announcement on the same day in which an analyst $i$ announces his forecast. Including the control variable AvForecast will help us to isolate the reaction to the message of a particular analyst. We control also for the average forecast squared, $A v F$ or $S q$, and the number of forecasts that compose such average, NumFor. Lastly, we include the interactions of AvForecast and AvForSq with NumFor. The final specifications are as follows:

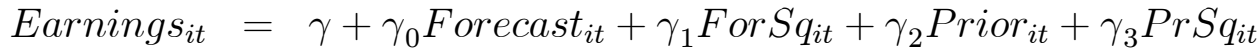

$$
\begin{aligned}
& +\gamma_{4} \text { Forecast }_{i t} * \text { Prior }_{i t}+\gamma_{5} \text { For S }_{i t} * \text { Prior }_{i t}+\zeta_{i t}
\end{aligned}
$$

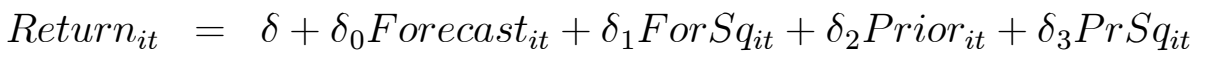

$$
\begin{aligned}
& +\delta_{4} \text { Forecast }_{i t} * \text { Prior }_{i t}+\delta_{5} \text { ForS }_{i t} * \text { Prior }_{i t}+\sum_{j=1}^{J} \delta_{j} X_{j i t}+\tau_{i t}
\end{aligned}
$$

, where $X$ refers to the control variables discussed above.

Our aim with this parametric specification is to test whether $\frac{\partial^{2} \text { Earnings }}{\partial \text { Forecast } P \text { Prior }}=\gamma_{4}+$ $2 \gamma_{5}$ Forecast $_{i t}<0$ and $\frac{\partial^{2} \text { Return }}{\partial \text { Forecast } 2 \text { Prior }}=\delta_{4}+2 \delta_{5}$ Forecast $_{i t}<0$. The results are displayed in Table 3. The coefficients of the interaction between Forecast and Prior are all statistically significant.

By operating with the coefficients $\gamma_{4}, \gamma_{5}$, we find that the predictions of our model are largely met for the earnings function. From the output of the $L S$ estimation, for instance, we have that $\gamma_{4}=-0.23$ and $\gamma_{5}=-39$. We conclude from these values that the marginal effect of Prior on the slope of the earnings function is negative unless the forecast is very pessimistic ${ }^{14}$. Similar conclusions are obtained for the $F E$ and Median specifications of the earnings function. These conclusions corroborate the findings in Subsection 6.1.2, that the slope of the earnings function is slower for analysts with higher Prior unless they announce pessimistic forecasts.

We reach similar (if quantitatively stronger) conclusions by operating the coefficients of the return function. The coefficients $\delta_{4}=-0.16$ and $\delta_{5}=5.95$ in the $L S$ estimation, for example, indicate that the slope of the return function is lower for analysts with higher values of Prior unless they announce extremely bad news (i.e. in the first five percentiles of the Forecast distribution).

\footnotetext{
$14-0.23-2 * 39 *$ Forecast $=0$ at the value of Forecast $=-0.003$, which is located approximately at the 15 th percentile of the distribution of Forecast.. For values of Forecast above -0.003 the cross-derivative has a negative sign.
} 


\section{Why are A nalysts Biased?}

As was mentioned in the Introduction, regulators have implemented reforms in the last years to tackle the bias in analysts' advice to investors. Choosing the right policy instrument to address such bias is clearly a complex issue that goes beyond the scope of this paper. Making the right choice, however, requires some understanding of the reasons why analysts are biased. In our opinion this understanding has not been achieved yet for the bias in earnings' forecasts. In this section we use the empirical strategy developed above to discriminate between two alternative hypotheses ${ }^{15}$ that have inspired recent alternative policies.

In the belief that investment banking conflicts of interests are significant in the industry, America's securities regulators imposed in April 2003 reforms to strengthen the internal separation between the investment banking and the research divisions of big brokerage houses. There is substantial evidence that this belief is well-founded. Very often, for instance, an analyst in the research division of a big house can find that the investment bank division is counselling the very same company that he is forecasting on. Such counselling is habitually related to corporate finance activities, like initial public offering ("IPOs"), seasoned equity offering ("SEOs"), mergers or acquisitions. In fact, analysts at big houses are frequently involved in these activities, consulting on possible deals, joining road shows and starting coverage of prospective or current corporate clients. Since big houses make most of their profits from corporate financing, analysts compensations can be strongly determined by their contribution to their employer seizing a bigger share of this profitable business (for evidence on this, see Unger [40], quoted in Boni and Womack [10]). It is often stated in the financial media that this has a strong impact on the priorities of analysts working for firms with investment banking divisions ${ }^{16}$.

Some authors have suggested, on the other hand, that analysts cooperate with the company's management in order to maintain and improve their access to it. Lim [29] has argued, for instance, that analysts can only have steady and timely access to relevant information through their contacts with company managers. More interestingly, Boni and Womack [10] have emphasised that one of the services that investors value most from analysts is their ability to arrange meetings for them with company executives. Both authors have argued that these may be the reasons why

\footnotetext{
${ }^{15}$ Common to both hypotheses about analysts' misaligned incentives is the belief that managers of the companies studied want them to be optimistic. Lim [29], for instance, states that "managers prefer favourable forecasts because these support higher capital valuations and, hence, their compensation levels".

${ }^{16}$ For instance, Boni and Womack [10] offer survey-based evidence that buy-side professionals believe that the desire to attract investment banking business for their firm motivates analysts far more than any possible concern for the accuracy of their predictions. Anecdotal evidence is strongly consistent with this belief. As an example, one Goldman Sachs analyst was quoted as listing in an internal email his three most important goals for 2000 as "1) Get more investment banking revenue 2) Get more investment banking revenue 3) Get more investment banking revenue" (The Economist [39])
} 
analysts seek to avoid painting a bleak picture of the company's future ${ }^{17}$. Regulation Fair Disclosure, introduced by the SEC in late 2001, to eliminate selective disclosure of material information, has been inspired by these arguments.

It is important to understand the different implications of the "investment banking" reason and the "management access" reason. Consider first the size of the brokerage house that employs the analyst. If the investment banking reason is true, analysts in bigger brokerage houses will be more biased than those in smaller brokerage houses. This is because only the biggest brokerage houses have an investment bank division, and can therefore expose their analysts to such conflicts of interest.

Under the "management access" reason analysts are eager to preserve managers' cooperation. There is evidence, however, that managers of a company also benefit from receiving analysts' coverage and want to encourage it. The reason is that firms covered by securities analysts are better known to investors and in general boost their share price ${ }^{18}$. Therefore we can regard the relationship between analysts and management as one where the parties need each other and are eager to obtain concessions from each other. Lim [29] has suggested that concessions by analysts could include biasing the earnings' forecast.

We posit that under the "management access" reason the relative "bargaining power" of the two parties influences the extent to which analyst incentives are misaligned. For example, analysts from big brokerage houses hold a strong position, as the high visibility that they provide is strongly coveted by management. Similarly older analysts and analysts that follow more companies hold a stronger position and are therefore less biased. On the other hand, when a company is more important and more widely covered, we expect their managers to enjoy more "bargaining power", and the forecasts made on those firms to be more biased.

We first provide preliminary evidence in support of the "management access" reason by identifying the determinants of Prior. We regress Prior on the size of the brokerage house, the number of companies that an analyst follows, the analyst's general experience, the company's size in terms of book value and market capitalisation, and the coverage that the company is receiving from analysts ${ }^{19}$. Since neither Prior nor the exogenous variables vary within an analyst-firm-quarter cell, we use only one observation per cell and drop the rest. Our results are displayed in Table 4.

We find that Prior is positively correlated with analyst coverage, book value and market capitalisation and negatively correlated with size of the brokerage size,

\footnotetext{
${ }^{17}$ Boni and Womack [10] report that $69.3 \%$ of institutional investors believe direct pressure from corporate management has a continuing effect on analysts research.

${ }^{18}$ Krigman, Shaw and Womack [28] conducted a survey among 578 firms that went public between 1993 and 1995 and conducted a SEO within three years of their IPO. They asked decision-makers at companies that had switched lead underwriters the main reasons for that decision. The main reason was revealed to be to "buy additional and influential analyst coverage from the new lead underwriter".

${ }^{19}$ We obtain the book value of a firm and its market capitalisation from COMPUSTAT and CRSP respectively, and the rest of the variables from $\mathrm{I} / \mathrm{B} / \mathrm{E} / \mathrm{S}$.
} 
the number of companies that the analyst follows and the analyst general experience. This is consistent with the "management access" reason. We interpret the preliminary finding that analysts from bigger brokerage houses are less biased than those from smaller houses as evidence against the "investment banking" reason.

The results in Table 4 seem to indicate that the bias of an analyst is correlated to certain variables related to his "bargaining power". Using the empirical strategy developed in Section 7, however, we can provide a better test of the "management access" hypothesis. If this hypothesis and our model are correct, an analyst working for a small brokerage house is very likely to have misaligned incentives. As a result, such analyst will predict above actual earnings if he makes an optimistic forecast, although not as much if his forecast is pessimistic. Correspondingly, the market will react to pessimistic but not to optimistic forecasts.

We repeat regressions (16) and (17), and substitute Prior by each of the variables that we found in Table 4 to be correlated with it. If our hypotheses are true, we expect to find $\frac{\partial^{2} \text { Earnings }}{\partial \text { Forecast } \partial X}>0$ and $\frac{\partial^{2} \text { Return }}{\partial F \text { orecast } \partial X}>0$ for the variables of brokerage size, number of companies that the analyst follows and his general experience and $\frac{\partial^{2} \text { Earnings }}{\partial F \text { Frecast } \partial X}<0$ and $\frac{\partial^{2} \text { Return }}{\partial \text { Forecast } \partial X}<0$ for the variables of coverage of the firm, and size of the firm (book value and market capitalisation). The results are displayed in Table 5.

Note first that the findings for the earnings function are largely consistent with the "management access" hypothesis. For instance, expected earnings are higher following an optimistic forecast if the analyst making it works in a big brokerage house and follows sparsely covered and small (in terms of book value) firms. The coefficients on number of companies that the analyst follows and market capitalisation also have the predicted sign but are not significant. In the case of market capitalisation this is probably due to the strong co-linearity with the coverage of the firm and its book value (the correlations of market capitalisation with them is $68 \%$ and $60 \%$ respectively). The coefficient on experience has, however, the wrong sign.

The findings for the return function do not support our hypothesis. Only two coefficients are significant, and the one on book value displays the wrong sign.

We confirm our results regarding the earnings function by running nonparametric regressions separately for sub-samples of high and low levels of our test variables. The results are plotted in Figures O-T. From Figure $\mathrm{O}$ we can see that analysts from bigger houses are less biased when they announce good news than analysts from smaller houses. Similarly, analysts following widely covered (Figure R) or bigger firms (Figures $\mathrm{S}$ and $\mathrm{T}$ ) are less biased when they announce good news, but not as much when they announce bad news. Figures $\mathrm{P}$ and Q do not seem to suggest that the variables capturing the number of firms followed by the analyst and his experience significantly affect the shape of the earnings function. 


\section{Concluding Remarks}

In this paper we have found evidence of a strategic interaction taking place in the stock market between investors and biased securities analysts. By using a simple model of cheap talk, we have obtained two intuitive predictions about the optimal reaction of investors to forecasts. We have then shown that the behaviour of investors in the real world is consistent with these predictions. At an academic level, our findings demonstrate the need to use a game-theoretical approach to study the effect of forecasts in the financial markets.

Our findings also have more practical implications. In the last years, regulators in the US have introduced a number of reforms in the securities industry aimed at curbing the misalignment of incentives between analysts and investors. This paper shows that investors as a whole are able to anticipate the misalignment of incentives and discount earnings forecasts accordingly. Investors are also able to discriminate across analysts, assigning less credibility to analysts with highly biased records. Contrary to what is sometimes believed, the average investor does not react naively to public announcements by analysts.

We have also shown, however, that lack of naivety on the investor's side does not imply that there is no scope for public intervention. This is easily understood by observing the flat right tail in the action function of Figures $\mathrm{C}$ and L. Even if investors attempt to discount the bias, the misalignment of incentives is detrimental to efficiency. The reason is that it prevents analysts from credibly transmitting good news about the firm's earnings, and therefore obstructs the efficient transmission of information in the market.

Lastly, we have provided some preliminary evidence regarding the causes for analysts' misalignment of incentives. We have shown that the "bargaining power" of the analysts versus the managers of the company may be an important explanatory element of this misalignment. As a result, Regulation Fair Disclosure may have helped to make the securities industry more efficient. 


\section{A Appendix}

\section{A.1 Figures}

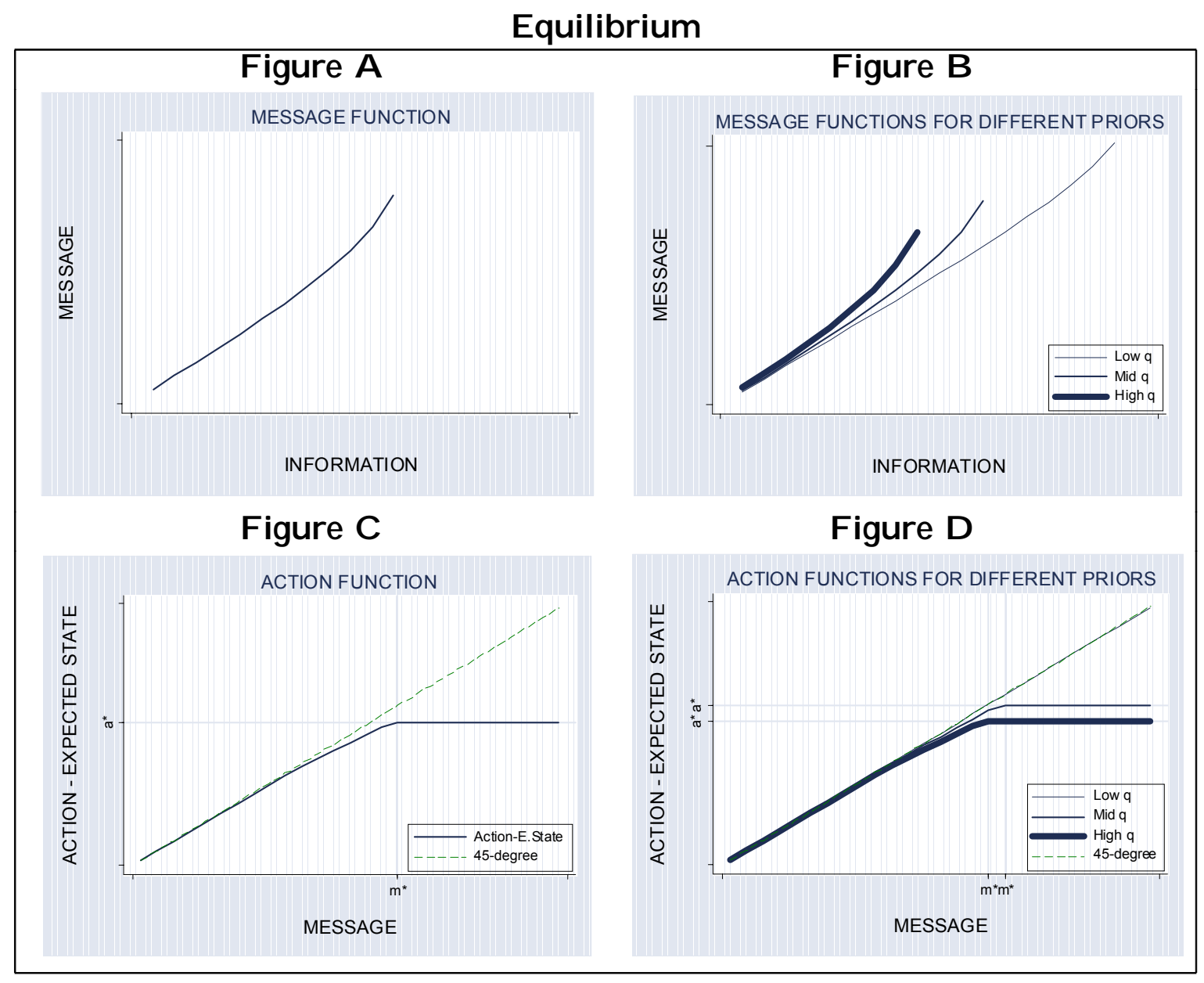


Other equilibria

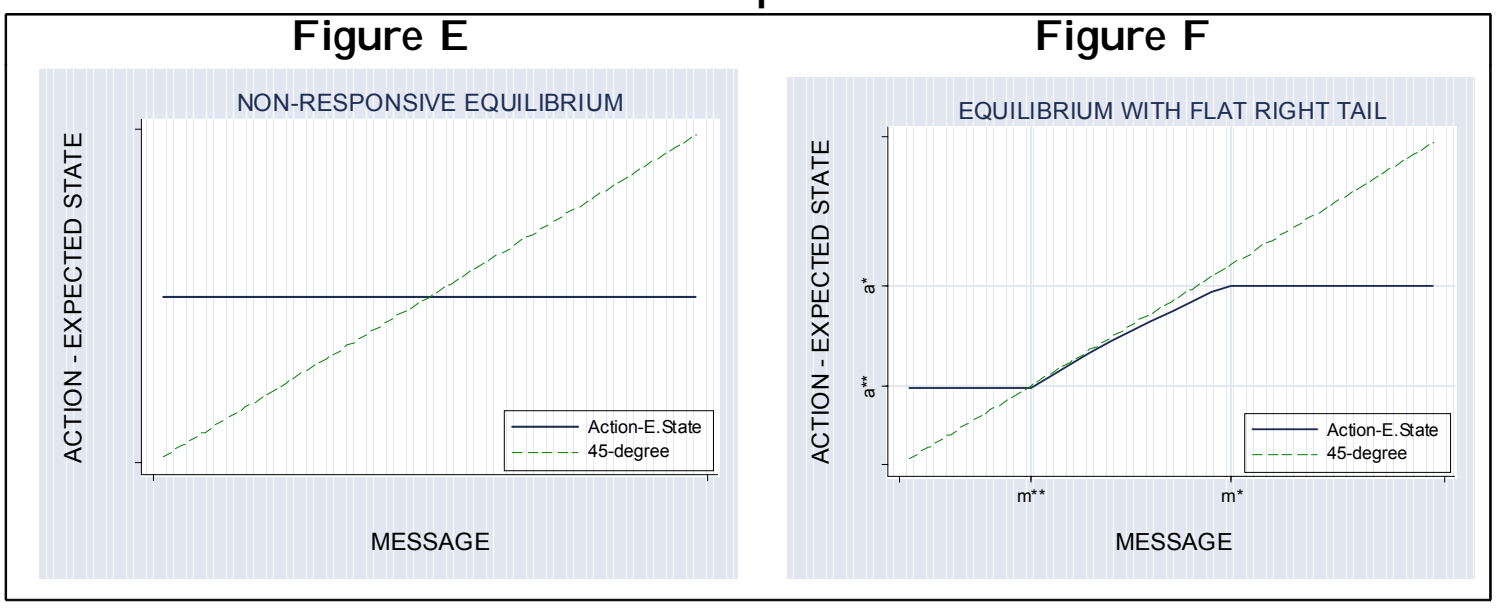

Cognitive Biases and $\mathrm{N}$ aive Investors

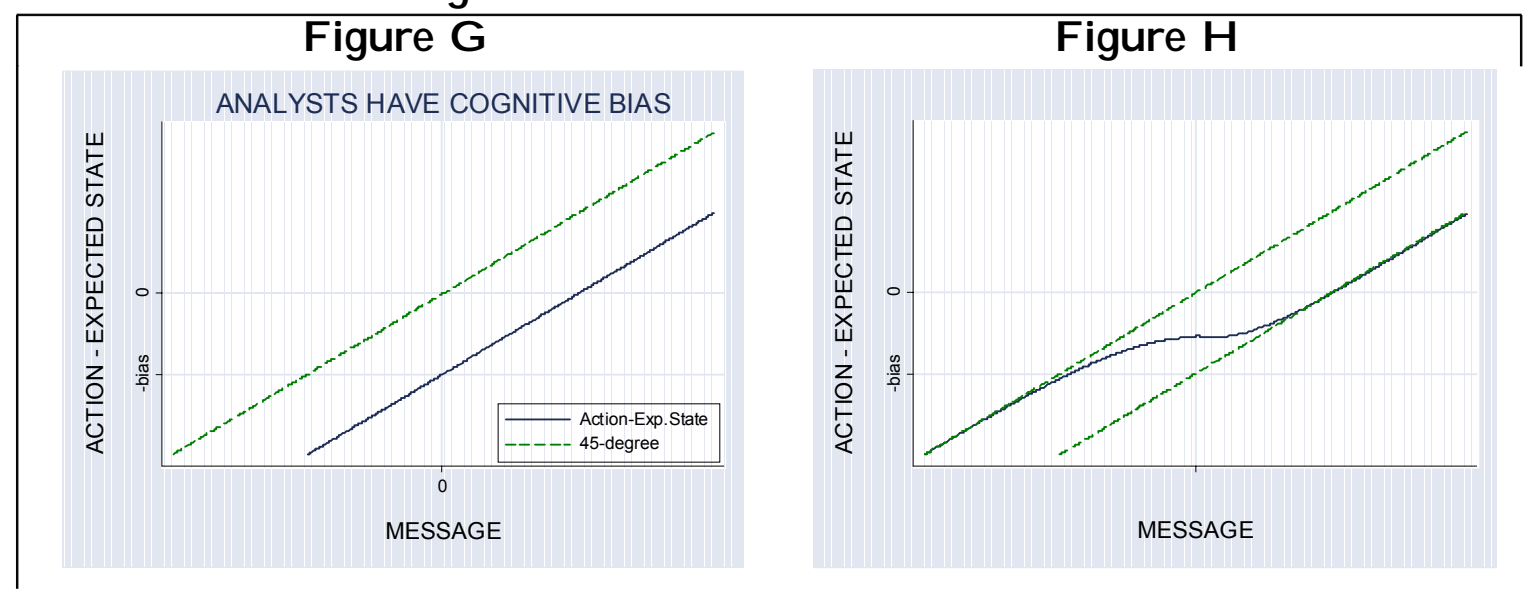




\section{Nonparametric R egressions of Earnings and Returns}

Figures K and L show nonparametric regressions of Earnings and Return on Forecast. The scale in the horizontal axis shows the percentiles of the Forecast variable. Forecast is the analyst forecast minus the prevailing consensus (consensus is the average forecast of the previous day in which a forecast was made on the same firm/quarter earnings). Earnings is the actual value of these earnings minus the consensus. Return is the abnormal return on the firm's share price on the day in which the forecast was made.

Figures $\mathrm{M}$ and $\mathrm{N}$ show nonparametric regressions of Earnings and Return on Forecast for analysts with different prior probability of being biased. For each analyst we compute the variable Prior (defined in Section 6), and split the sample in five quintiles according to this variable. q1 (the thinner line) refers to the quintile of analysts with the lowest value of Prior. We run the regressions separately for each quintile.

We use a normal kernel, optimal bandwidth (1.6*Standard Deviation of Forecast*Number of Observations) and 50 grid points. The confidence intervals are calculated with bootstrapping techniques (samples with replacement and 500 replications). The scale in the horizontal axis shows the percentiles of the Forecast variable.

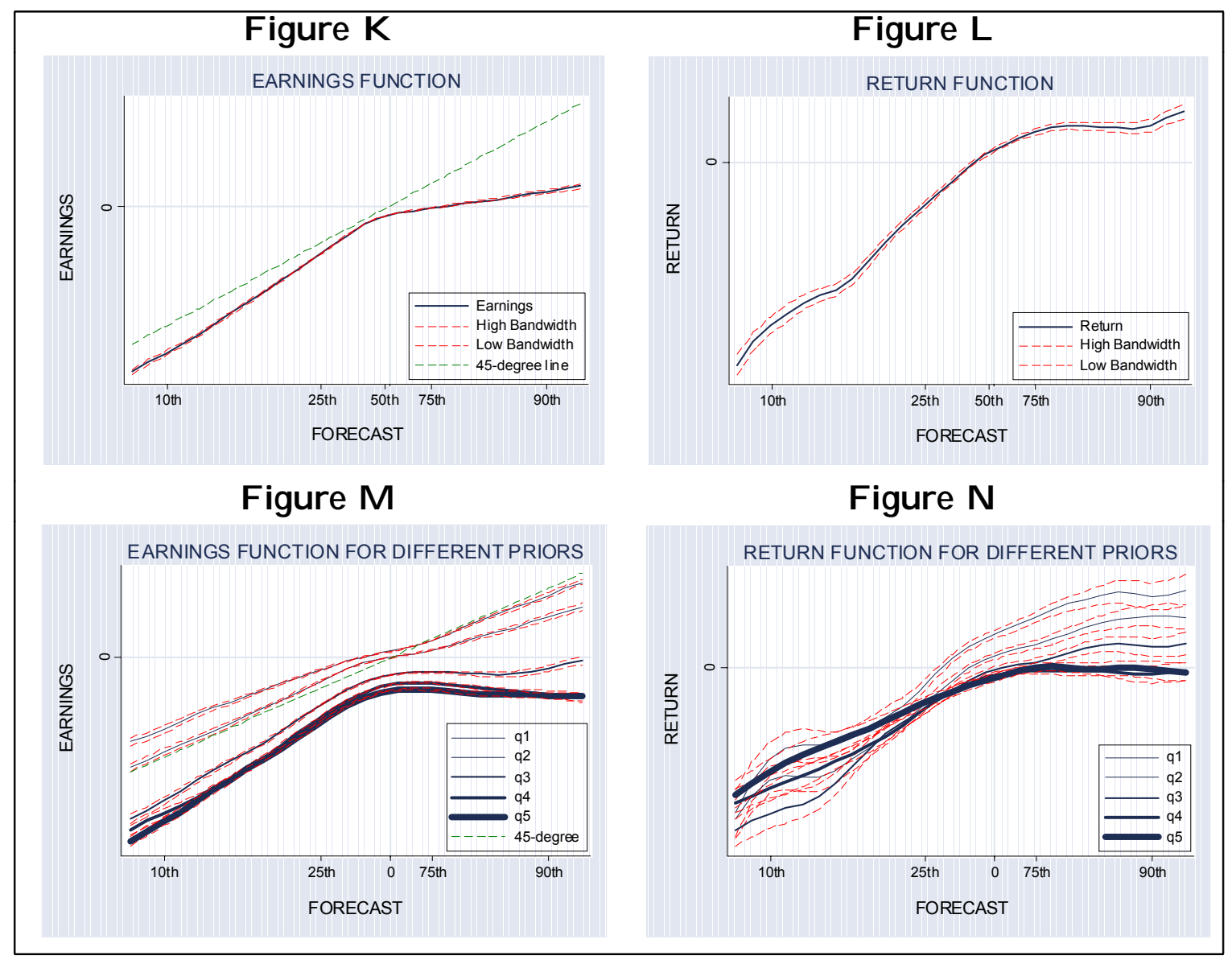




\section{The Importance of R elative Bargaining Power}

Figures O-T show the Earnings and Return regressions for different analyst and firm characteristics. The firm characteristics are defined in Table 4. We use the same kernel, optimal bandwidths, grid points and bootstrapping techniques as in Figures K-N. The scale in the horizontal axis shows the percentiles of the Forecast variable.

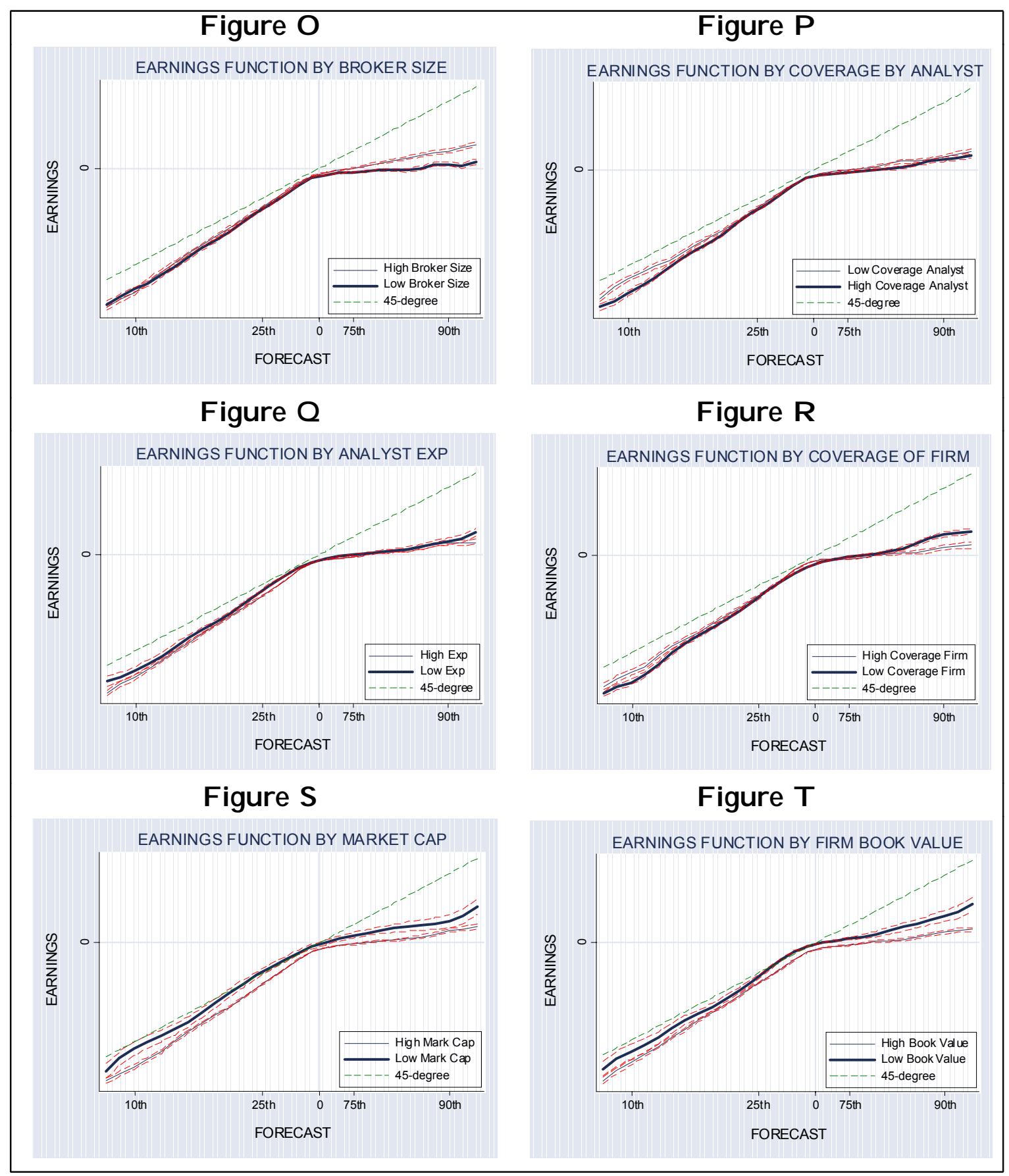




\section{A.2 Tables}

\section{Table 1 \\ Summary Statistics}

This table reports the summary statistics. Forecast is the analyst forecast minus the prevailing consensus (consensus is the average forecast of the previous day in which a forecast was made on the same firm/quarter earnings). Earnings is the actual value of these earnings minus the consensus. Return is the abnormal return on the firm's share price on the day in which the forecast was made. Forecasts per firm/quarter is the number of forecasts that were made on the earnings of each firm/quarter combination. Similarly for Forecasts per firm/quarter/analyst. Analysts per firm/quarter is the number of analysts that issued at least one forecast on the earnings of each firm/quarter combination. Firms per analyst/quarter is the number of firms for which an analyst issued at least one forecast in a quarter. Forecast horizon is the number of days between the forecast announcement and the announcement of actual earnings.

\begin{tabular}{l|ccccc} 
& Mean & S.D. & Median & $\mathrm{p} 25$ & $\mathrm{p} 75$ \\
\hline Forecast & -0.00039 & 0.00339 & -0.00006 & -0.00107 & 0.00064 \\
Earnings & -0.00130 & 0.00688 & -0.00002 & -0.00190 & 0.00099 \\
Forecast-Earnings & 0.00090 & 0.00636 & 0 & -0.00090 & 0.00113 \\
Return & -0.00089 & 0.03635 & -0.00067 & -0.01639 & 0.01555 \\
Forecasts per day & 1.35 & 1.15 & 1 & 1 & 1 \\
Forecasts per firm/quarter & 9.78 & 11.14 & 6 & 3 & 12 \\
Analysts covering a firm/quarter & 6.07 & 5.44 & 4 & 2 & 8 \\
Firms covered by analyst/quarter & 7.38 & 8.70 & 6 & 3 & 10 \\
Forecast horizon (days) & & & & & \\
Forecasts per analyst/firm/quarter & 2.12 & 1.22 & 2 & 1 & 3 \\
& & & & & \\
\end{tabular}




\section{Table 2 \\ Pooled Earnings and Return Regressions}

This table reports the regressions of Earnings and Returns on Forecasts. These three variables are defined as in Table 1. All analyst-firm pairs are pooled together. ForSq is the Forecast Squared. LReturn is the one-day lagged Return variable. Y\&Q accounts for year and quarter dummies. LS accounts for standard least squares. FE regressions include analyst-firm dummies. Median accounts for median (quantile) regressions. The Standard Errors (in parentheses) are robust and adjusted for firms-quarters correlation for the LS and FE regressions. The number of observations is 1,178,792. *** denotes significant at the $1 \%$ level.

\begin{tabular}{c|ccc|ccc} 
& \multicolumn{3}{|c|}{ Earnings } & \multicolumn{3}{c}{ Return } \\
& LS & FE & Median & LS & FE & Median \\
\hline Forecast & $0.65^{* * *}$ & $0.66^{* * *}$ & $0.76^{* * *}$ & $0.59^{* * *}$ & $0.58^{* * *}$ & $0.19^{* * *}$ \\
& $(0.006)$ & $(0.005)$ & $(0.0005)$ & $(0.02)$ & $(0.02)$ & $(0.01)$ \\
ForSq & $-28.2^{* * *}$ & $-14.6^{* * *}$ & $-19.4^{* * *}$ & $-16.0^{* * *}$ & $-7.31^{* * *}$ & $-9.47^{* * *}$ \\
& $(0.88)$ & $(0.66)$ & $(0.049)$ & $(2.13)$ & $(2.22)$ & $(1.41)$ \\
LReturn & & & & & & \\
& & & & $0.01^{* * *}$ & $0.007^{* * *}$ & $0.003^{* * *}$ \\
& & & & $(0.002)$ & $(0.001)$ & $(0.0009)$ \\
Y\&Q Ef. & Yes & Yes & No & Yes & Yes & No \\
Adj.R & $16 \%$ & $37 \%$ & $13 \%$ & $0.5 \%$ & $11 \%$ & $0.05 \%$
\end{tabular}




\section{Table 3}

Regressions including the effect of the Prior probability that the analyst is biased

This table reports the regressions of Earnings and Returns on Forecasts and Prior (the prior probability that the analyst is biased). Table 1 has the definitions of the first three variables, ForSq and Y\&Q Ef.. Prior is computed as the (weighted) percentage of times that the analyst has forecasted above the actual value in the past. The weights (defined in Section 6) are higher for more recent forecasts. PrSq is the variable Prior squared. Controls include LReturn, the average forecast by other analysts on the same day and firm/quarter on which the analyst issued his forecast, the average forecast squared, the number of forecasts that compose this average, and the interactions of the average forecasts and its square with the number of forecasts the compose the average. LS, FE and Median regressions are defined as in Table 2. The Standard Errors (in parentheses) are robust and adjusted for firms-quarters correlation for the LS and FE regressions. ***, ** and * denote significant at the 1\%,5\% and 10\% level. Regressions include a constant. The number of observations is 965,527 .

\begin{tabular}{|c|c|c|c|c|c|c|}
\hline & \multicolumn{3}{|c|}{ Earnings } & \multicolumn{3}{|c|}{ Return } \\
\hline & LS & $\mathrm{FE}$ & Median & LS & $\mathrm{FE}$ & Median \\
\hline \multirow[t]{2}{*}{ Forecast } & $0.69^{* * *}$ & $0.69^{* * *}$ & $0.84^{* * *}$ & $0.34^{* * *}$ & $0.35^{* * *}$ & $0.16^{* * *}$ \\
\hline & $(0.009)$ & $(0.007)$ & $(0.001)$ & $(0.03)$ & $(0.03)$ & $(0.02)$ \\
\hline \multirow[t]{2}{*}{ ForSq } & $-19.1^{* * *}$ & $-11.7^{* * *}$ & $-5.96 * * *$ & $-11.7^{* * *}$ & 3.06 & -3.83 \\
\hline & $(1.32)$ & $(1.03)$ & $(0.11)$ & $(3.27)$ & $(3.26)$ & $(2.43)$ \\
\hline \multirow[t]{2}{*}{ Prior } & $-0.01 * * *$ & $-0.008^{* * *}$ & $-0.002^{* * *}$ & $-0.01^{* * *}$ & $-0.01 * * *$ & $-0.006^{* * *}$ \\
\hline & $(0.0002)$ & $(0.0002)$ & $(0.00002)$ & $(0.0006)$ & $(0.0008)$ & $(0.0006)$ \\
\hline \multirow[t]{2}{*}{ PrSq } & $0.009^{* * *}$ & $0.007 * * *$ & $0.001^{* * *}$ & $0.008^{* * *}$ & $0.009^{* * *}$ & $0.005^{* * *}$ \\
\hline & $(0.0002)$ & $(0.0002)$ & $(0.00003)$ & $(0.0007)$ & $(0.0008)$ & $(0.0007)$ \\
\hline \multirow[t]{2}{*}{ Prior*For. } & $-0.23^{* * *}$ & $-0.18^{* * *}$ & $-0.35^{* * *}$ & $-0.16^{* *}$ & $-0.26^{* * *}$ & $-0.23^{* * *}$ \\
\hline & $(0.02)$ & $(0.02)$ & $(0.003)$ & $(0.08)$ & $(0.08)$ & $(0.075)$ \\
\hline \multirow[t]{2}{*}{ Prior*ForSq } & $-39.0^{* * *}$ & $-12.0^{* * *}$ & $-63.7^{* * *}$ & 5.95 & $-19.9^{* *}$ & $-12.8^{*}$ \\
\hline & $(3.13)$ & $(2.63)$ & $(0.32)$ & $(7.99)$ & $(8.25)$ & $(7.06)$ \\
\hline Y\&Q Ef. & Yes & Yes & No & Yes & Yes & No \\
\hline Controls & No & No & No & Yes & Yes & Yes \\
\hline Adj. $R^{2}$ & $18 \%$ & $40 \%$ & $14 \%$ & $0.9 \%$ & $12 \%$ & $0.2 \%$ \\
\hline
\end{tabular}




\section{Table 4 The Determinants of the Prior Probability that the Analyst is Biased}

This table reports the regressions of the prior probability that the analyst (analyst-firm pair) is a biased type on a number of analyst and firm characteristics. Prior is defined as in Table 3. Broker Size is the number of analysts that are employed in a brokerage house in a year. Coman is the number of firms on which the analyst issues at least one forecast in a year. Ancom is the number of analysts that issue a forecast on the firm in a year. GenEx is the number of quarters in which the analyst has issued at least one forecast. Marcap is the end-of-year market capitalisation of the firm. Book is the end-of-year book value of the firm. For each year and variable we split the sample in ten deciles and, to avoid endogeneity problems, we assign every analyst-firm pair the decile of the previous year. The results are unchanged if we include the variables in absolute levels and/or in their current year values. ${ }^{* * *}$ denotes significant at the $1 \%$ level. The standard errors (in parentheses) are heteroskedasticity robust. The number of observations is 477,434 .

\begin{tabular}{c|cc} 
& \multicolumn{2}{|c}{ Prior } \\
& Coefficient & S.E. \\
\hline Broker Size & $-0.003^{* * *}$ & $(0.0005)$ \\
ComAn & $-0.003^{* * *}$ & $(0.003)$ \\
GenExp & $-0.014^{* * *}$ & $(0.002)$ \\
AnCom & $0.003^{* * *}$ & $(0.0004)$ \\
MarCap & $0.004^{* * *}$ & $(0.0005)$ \\
Book & $0.009^{* * *}$ & $(0.0003)$ \\
& \multicolumn{2}{|c}{ Yes } \\
Year \& Quarter Effects & \multicolumn{2}{|c}{ Yes } \\
Fixed Effects & \multicolumn{2}{|c}{$60 \%$} \\
Adj. R &
\end{tabular}




\section{Table 5 \\ The Importance of Relative Bargaining Power}

This table reports the effect on the Earnings and Return regression of interacting Forecast and ForSq (defined in Table 2) with a number of firm and analyst characteristics (defined in Table 4). The controls are defined in Table 3. S.E. (in parentheses) are robust and adjusted for firms-quarters correlation. ${ }^{* * *}$ and $* *$ denote significant at the $1 \%$ and $5 \%$ level. The number of observations is $1,047,479$.

\begin{tabular}{c|cccc} 
& \multicolumn{2}{|c}{ Earnings } & \multicolumn{2}{c}{ Return } \\
& Coefficient & S.E. & Coefficient & S.E. \\
\hline Broker Size*For & $0.02^{* * *}$ & $(0.003)$ & $0.03^{* * *}$ & $(0.009)$ \\
Broker Size*ForSq & $2.12^{* * *}$ & $(0.40)$ & 1.33 & $(0.95)$ \\
Coman*For & 0.0008 & $(0.002)$ & -0.003 & $(0.008)$ \\
Coman*ForSq & 0.50 & $(0.32)$ & 0.57 & $(0.82)$ \\
GenExp*For & -0.005 & $(0.008)$ & 0.03 & $(0.02)$ \\
GenExp*ForSq & $-4.28^{* * *}$ & $(0.93)$ & -0.83 & $(2.30)$ \\
& & & &
\end{tabular}




\section{A.3 Proofs}

We use the following notation throughout the Appendix. First of all, $p=q /(1-q)$. Further, $F(m, x)=0$ is the implicit function of $x$ on $m$ defined by $(5) . \quad F(m, x)$ is a function of two exogenous variables, $m$ and $x . F\left(m, x_{0}\right)$ is a function of one exogenous variable $m$, where $x_{0}$ is a parameter. Lastly, $F\left(m_{0}, x_{0}\right)$ is a specific value, or alternatively the function $F(m, x)$ evaluated at the values $m_{0}$ and $x_{0}$.

\section{A.3.1 Proof of Lemma 2}

Define $f(x \mid m, v)$ as the posterior density function of $x$ given $m$ and the equilibrium message strategy $v$. Problem (1) becomes:

$$
\begin{aligned}
& \underset{a}{\operatorname{Max}}-\int(a-x)^{2} f(x \mid m, v) d x \\
& \underset{a}{\operatorname{Max}}\left\{-a^{2}+2 a \int x f(x \mid m, v) d x-\int x^{2} f(x \mid m, v) d x\right\}
\end{aligned}
$$

The solution of this problem is $a=E[x \mid m, v]$, given by (2) when the message is believed to having been chosen in mixed strategies and by (3) when it is believed to having been chosen in pure strategies.

\section{A.3.2 Proof of Proposition 3}

From the discussion in the main text we have that a fully-responsive equilibrium is impossible if the function $a(m)$ is not increasing.

First of all we rule out a fully-responsive equilibrium in which mixed strategies are used in the message function. Assume that $m_{1}$ and $m_{2}$, with $m_{1} \neq m_{2}$, are both sent in equilibrium with some probability when $x=x_{1}$. If the analyst that observes $x_{1}$ is indifferent between both messages, it must be that $a\left(m_{1}\right)=a\left(m_{2}\right)$. But in this case the action function cannot be strictly increasing and the equilibrium cannot be fully responsive.

Assume pure strategies now. An equilibrium where the action is always increasing with the message must meet equation (5) for all $x$. We show next that there is a value of $x, x_{0}$, such that $F\left(m, x_{0}\right)<0 \forall m$, so that (5) cannot be met.

Take $x_{0}=\frac{\sigma^{2}}{b p}$. If $m \leq x_{0}$, the inequality is immediate. If $m>x_{0}$, then $m^{2}>x_{0}^{2}$. The exponential function has the property that $\exp (z)>1+z$. Therefore $F\left(m, x_{0}\right)<$ $m-x_{0}-b-b p\left(1+\left(m^{2}-x_{0}^{2}\right) / 2 \sigma^{2}\right)=m-\frac{\sigma^{2}}{2 b p}-b-b p-\frac{b p}{2 \sigma^{2}} m^{2}$. This last expression reaches a maximum at $m_{0}=\frac{\sigma^{2}}{b p}$, at which it is equal to $-b(1+p)<0$. So $(5)$ is not defined at the point $x_{0}=\frac{\sigma^{2}}{b p}$. 


\section{A.3.3 Proof of Proposition 4}

We prove Proposition 4 using the following steps. First we study condition (5) and derive a number of technical properties about it. We follow by showing that conditions 1-4 of Proposition 4 fully characterise an equilibrium. Finally we then characterise all the other possible continuous equilibria of this model and show that they are less responsive that the one identified in Proposition 4.

\section{Lemma 6}

Lemma 6 Consider the implicit equation of $x$ on $m, F(m, x)=0$. For any set of values $b_{0}>0, q_{0}>0$ and $\sigma_{0}^{2}>0$ :

1. There always exists a value of $x, x_{0}$, such that this equation has at least one solution $m_{0}$, and another value $x_{1}$ such that this equation has no solution.

2. There exists only one value of $x, \widetilde{x}$, such that this equation has a unique solution, $\tilde{m}$. For every $x$ strictly lower than $\widetilde{x}$ the equation has exactly two solutions, $m^{1}(x)$ and $m^{2}(x)$, with $m^{1}(x)<\widetilde{m}<m^{2}(x) \forall x$.

3. The function $m^{1}(x)$ satisfies the following properties:

(a) $m^{1}(x)>x$

(b) $\frac{\partial m^{1}(x)}{\partial x}>1$

(c) $\frac{\partial^{2} m^{1}(x)}{\partial x^{2}}>0$

(d) $\frac{\partial^{2} m^{1}(x)}{\partial x \partial q}>0$

\section{Proof of Lemma 6}

Part 1 The second statement derives directly from Proposition 3. For the first statement distinguish two cases, depending on whether $p_{0}=q_{0} /\left(1-q_{0}\right)$ is higher or lower than 1.

1. If $p_{0}<1$, make $x_{0}=-2 b_{0}$ and consider the function $F\left(m,-2 b_{0}\right) . F\left(m,-2 b_{0}\right)$ is a continuous function $\forall m$ and notice that $F\left(0,-2 b_{0}\right)>0$ and $F\left(-2 b_{0},-2 b_{0}\right)=$ $-b_{0}-b_{0} p_{0}<0$. It follows that there is a $\left.m_{0} \in\right]-2 b_{0}, 0\left[\right.$ such that $F\left(m_{0},-2 b_{0}\right)=$ 0 . Equation 5 has a solution.

2. If $p_{0} \geq 1$, take $x_{0}=-2 b_{0} p_{0}$, and consider the function $F\left(m,-2 b_{0} p_{0}\right) . F\left(m,-2 b_{0} p_{0}\right)$ is a continuous function $\forall m$ and $F\left(0,-2 b_{0} p_{0}\right)>0$ and $F\left(-2 b_{0} p_{0},-2 b_{0} p_{0}\right)=$ $-b_{0}-b_{0} p_{0}<0$. It follows that there is a $\left.m_{0} \in\right]-2 b_{0} p_{0}, 0\left[\right.$ such that $F\left(m_{0},-2 b_{0} p_{0}\right)=$ 0 and equation 5 has a solution. 
Part 2 We first show that if equation (5) has a solution for a certain $x_{0}$, then it has exactly two solutions for every value of $x$ below $x_{0}$. Make $m_{0}$ as the solution of (5) for $x_{0}$ and make $k=m_{0}-x_{0}$, where clearly $k>0$. Take some value $x_{1}<x_{0}$ and consider the function $F\left(m, x_{1}\right) . F\left(m, x_{1}\right)$ is continuous and twice differentiable $\forall m$, and note that $F\left(x_{1}, x_{1}\right)=-b_{0}\left(1+p_{0}\right)<0$ and that $F\left(x_{1}+k, x_{1}\right)>0$. By L'Hôpital rule,

$$
\lim _{m \rightarrow+\infty} \frac{m-x_{1}}{\left.1+p_{0} \exp \left(\left(m^{2}-x_{1}^{2}\right) / 2 \sigma_{0}^{2}\right)\right)}=\frac{1}{\left.m p_{0} \exp \left(\left(m^{2}-x_{1}^{2}\right) / 2 \sigma_{0}^{2}\right)\right)}=0
$$

It follows that $\exists m_{2}$ such that $\left.\forall m \geq m_{2}, m-x_{1}<b_{0}\left(1+p_{0} \exp \left(\left(m^{2}-x_{1}^{2}\right) / 2 \sigma_{0}^{2}\right)\right)\right)$. For those values of $m$, we have that $F\left(m, x_{1}\right)<0$. In particular, note that $F\left(m_{2}, x_{1}\right)<$ 0 , and that $m_{2}>x_{1}+k$. We have found three values, $x_{1}<x_{1}+k<m_{2}$ such that $F\left(x_{1}, x_{1}\right)<0, F\left(x_{1}+k, x_{1}\right)>0$ and $F\left(m_{2}, x_{1}\right)<0$. Consequently, there are two values $m_{11}$ and $m_{12}$, such that $x_{1}<m_{11}<x_{1}+k<m_{12}<m_{2}$ and $F\left(m_{11}, x_{1}\right)=F\left(m_{12}, x_{1}\right)=0$.

Next we show that equation (5) has only two solutions for every $x$. Imagine that there is another value $m_{13}$ such that $F\left(m_{13}, x_{1}\right)=0$. If that is the case, there are two values, $m_{3} \in\left(m_{11}, m_{13}\right)$ and $m_{4} \in\left(m_{13}, m_{12}\right)$ such that $\frac{\partial F\left(m_{3}, x_{1}\right)}{\partial m}=\frac{\partial F\left(m_{4}, x_{1}\right)}{\partial m}=0$, and another value, $m_{5} \in\left(m_{3}, m_{4}\right)$ such that $\frac{\partial^{2} F\left(m_{5}, x_{1}\right)}{\partial m^{2}}=0$. But it is easy to see that $\frac{\partial^{2} F\left(m, x_{1}\right)}{\partial m^{2}}<0 \forall m$, hence a contradiction and (5) can only have two solutions.

From Proposition 3 and Part 1 of Lemma 6, we know that the real set $H_{b_{0}, p_{0}, \sigma_{0}}=$ $\left\{x: \exists m / F\left(m, x, b_{0}, p_{0}, \sigma_{0}\right)=0\right\}$ (henceforth $H$ ) is non-empty and bounded from above. We also know that if $x_{0}$ belongs to the $H$, then every $x<x_{0}$ also belongs to it. It follows that $H$ has a supreme value, $\widetilde{x}$, and it is of the form $(-\infty, \widetilde{x}[$ or $(-\infty, \widetilde{x}]$. We finish the proof of this part by showing that equation (5) has a unique solution for $\widetilde{x}$.

We first show that at least one solution exists. Because $\widetilde{x}$ is the supreme of $H$, we can build a strictly increasing sequence $\left\{x_{n}\right\}_{n=1}^{\infty}$ such that $\lim _{n \rightarrow \infty} x_{n}=\widetilde{x}$, and for every $x_{n}$ there exist two values $m_{n, 1}$ and $m_{n, 2}$, with $m_{n, 1}<m_{n, 2}$ and $\left(x_{n}, m_{n, 1}\right)$ and $\left(x_{n}, m_{n, 2}\right)$ satisfy (5). Call $m_{n}=m_{n, 1}$ and note that the sequence $\left\{m_{n}\right\}_{n=1}^{\infty}$ is bounded. It is clearly bounded from below, since $\forall n, m_{n}>x_{n}>x_{I}$, where $x_{I}$ is the first term of the sequence that converges to $\widetilde{x}$. It is also bounded from above. To see that, make $s=\max \left(\left|x_{I}\right|,|\widetilde{x}|\right)$. Since $\lim _{m \rightarrow+\infty} \frac{m+s}{\left.1+p_{0} \exp \left(\left(m^{2}-s^{2}\right) / 2 \sigma_{0}^{2}\right)\right)}=0, \exists m_{0}$ such that $\forall m \geq m_{0}, \frac{m+s}{\left.1+p_{0} \exp \left(\left(m^{2}-s^{2}\right) / 2 \sigma_{0}^{2}\right)\right)}<b_{0}$. Therefore, $\forall m \geq m_{0}$ and any $n$ we have that $F\left(m, x_{n}\right)<F(m, s)<0 \forall n$. So the sequence is bounded from above by the value $m_{0}$.

Since the sequence $\left\{m_{n}\right\}_{n=1}^{\infty}$ is bounded, we can build a subsequence $\left\{m_{n_{k}}\right\}_{k=1}^{\infty}$ that converges to a certain $\widetilde{m}$. Therefore the sequence in $R^{2}\left\{\left(x_{n_{k}}, m_{n_{k}}\right)\right\}_{k=1}^{\infty}$ converges to $(\widetilde{x}, \widetilde{m})$.

Consider the function of two variables $F(x, m)$, which is continuous in the point 
$(\widetilde{x}, \widetilde{m})$. Since $\lim _{k \rightarrow+\infty}\left(x_{n_{k}}, m_{n_{k}}\right)=(\widetilde{x}, \widetilde{m})$, we have that $\lim _{k \rightarrow+\infty} F\left(x_{n_{k}}, m_{n_{k}}\right)=F(\widetilde{x}, \widetilde{m})$ and since $F\left(x_{n_{k}}, m_{n_{k}}\right)=0, F(\widetilde{x}, \widetilde{m})=0$ and $m=\widetilde{m}$ is a solution to equation (5).

Lastly, we show that the solution $\widetilde{m}$ is unique. Consider the function $F(m, \widetilde{x})$, which is continuous and twice differentiable. Assume that there are two values $\widetilde{m}_{1}<$ $\widetilde{m}_{2}$ that satisfy $F\left(\widetilde{m}_{1}, \widetilde{x}\right)=F\left(\widetilde{m}_{2}, \widetilde{x}\right)=0$. If that is the case, there will be a value $\left.m_{3} \in\right] \widetilde{m}_{1}, \widetilde{m}_{2}\left[\right.$ such that $\frac{\partial F\left(m_{3}, \widetilde{x}\right)}{\partial m}=0$. Because $\frac{\partial^{2} F(m, \widetilde{x})}{\partial m^{2}}<0, F(m, \widetilde{x})$ has a relative maximum at $m_{3}$, and since $F\left(\widetilde{m}_{1}, \widetilde{x}\right)=F\left(\widetilde{m}_{2}, \widetilde{x}\right)=0$, we have that $F\left(m_{3}, \widetilde{x}\right)>0$. Consider now the continuous function of $\mathrm{x}, F\left(m_{3}, x\right)$. From the argument above, $F\left(m_{3}, \widetilde{x}\right)>0$. On the other hand, $F\left(m_{3}, m_{3}\right)<0$ and $m_{3}>\widetilde{x}$. Consequently there must be a $\left.x_{00} \in\right] \widetilde{x}, m_{3}\left[\right.$ such that $F\left(m_{3}, x_{00}\right)=0$. But if that is the case $\widetilde{x}$ is not the supreme of $H$, which is a contradiction.

Part 3 A result that need to prove this part of the Lemma is the fact that, given $x_{1}<\widetilde{x}$ with solutions $m_{1}$ and $m_{2}$ associated with $x_{1}$ and the function of $m, F\left(m, x_{1}\right)$, then if $m_{1}<m_{2}$, then $\frac{\partial F\left(m_{1}, x_{1}\right)}{\partial m}>0$ and $\frac{\partial F\left(m_{2}, x_{1}\right)}{\partial m}<0$. The proof is as follows. It was shown in the previous subsection that $F\left(m, x_{1}\right)<0 \forall m<m_{1}, F\left(m, x_{1}\right)>0$ $\forall m \in\left(m_{1}, m_{2}\right)$ and $F\left(m, x_{1}\right)<0 \forall m>m_{2}$. It was shown also that $\frac{\partial^{2} F\left(m, x_{1}\right)}{\partial m^{2}}<0$ $\forall m$ and that there is a point $m_{3}, m_{3} \in\left(m_{1}, m_{2}\right)$ such that $\frac{\partial F\left(m_{3}, x_{1}\right)}{\partial m}=0$. It is an immediate conclusion from these findings that $\frac{\partial F\left(m_{1}, x_{1}\right)}{\partial m}>0$ and $\frac{\partial F\left(m_{2}, x_{1}\right)}{\partial m}<0$.

We also use the fact that, given $\widetilde{x}$ and $\widetilde{m}, F^{\prime}(\widetilde{m}, \widetilde{x})=0$. The proof is as follows. It was shown in the previous subsection that we can take a strictly increasing sequence $\left\{x_{n}\right\}_{n=1}^{\infty}$ that converges to $\widetilde{x}$ and two sequences $\left\{m_{n 1}\right\}_{n=1}^{\infty}$ and $\left\{m_{n 2}\right\}_{n=1}^{\infty}$ that converge to $\widetilde{m}$ such that $m_{n 1}<m_{n 2}$ and $\left\{x_{n}, m_{n 1}\right\}$ and $\left\{x_{n}, m_{n 2}\right\}$ are solutions to (5).

Assume that $\frac{\partial F(\tilde{m}, \widetilde{x})}{\partial m}>0$, and consider the function $F(x, m)$, which is continuous at $(\widetilde{x}, \widetilde{m})$. Since $\lim _{n \rightarrow+\infty}\left(x_{n}, m_{n 2}\right)=(\widetilde{x}, \widetilde{m})$, we have that $\lim _{n \rightarrow+\infty} F\left(x_{n}, m_{n 2}\right)=$ $F(\widetilde{x}, \widetilde{m}) \leq 0$, which is a contradiction. Similarly if we assume that $\frac{\partial F(\widetilde{m}, \widetilde{x})}{\partial m}<0$ we reach a contradiction, so that necessarily $\frac{\partial F(\tilde{m}, \tilde{x})}{\partial m}=0$.

We can now proceed to prove the different subparts of Part 3.

Subpart 3.a From (5), this is an immediate result.

Subpart 3.b Taking derivatives to (5), we have that :

$$
\frac{\partial m}{\partial x}=\frac{\frac{\partial F(m, x)}{\partial x}}{\frac{\partial F(m, x)}{\partial m}}=\frac{1-\frac{b p x}{\sigma^{2}} \exp \left(\left(m^{2}-x^{2}\right) / 2 \sigma^{2}\right)}{1-\frac{b p m}{\sigma^{2}} \exp \left(\left(m^{2}-x^{2}\right) / 2 \sigma^{2}\right)}
$$

From the Introduction to the proof of Part 3 we have that $\frac{\partial F(m, x)}{\partial m}>0$. We also know that $\frac{\partial F(m, x)}{\partial x}>0$, as $m>x$. Therefore both numerator and denominator are positive numbers and it is immediate that $\frac{\partial m}{\partial x}>1$.

Subpart 3.c Differentiating (5) twice over $x$ and rearranging we have that

$$
\frac{\partial^{2} m}{\partial x^{2}}=\frac{\exp \left(-x^{2} / 2 \sigma^{2}\right) \frac{p b}{\sigma^{2}}}{\frac{\partial F(m, x)}{\partial m}}\left\{\left(\left(\frac{\partial m}{\partial x}\right)^{2}-1\right)+\frac{1}{\sigma^{2}}\left(m\left(\frac{\partial m}{\partial x}\right)-x\right)^{2}\right\}
$$


Both numerator and denominator of the fraction are positive numbers. Furthermore, the term in brackets is unambiguously positive, since from Subpart 3.b we have that $\frac{\partial m}{\partial x}>1$. Consequently $\frac{\partial^{2} m}{\partial x^{2}}>0$.

Subpart 3.d Differentiating (5) twice over $x$ and over $p$.

$$
\frac{\partial^{2} m}{\partial x \partial p}=\frac{\left(\frac{b}{\sigma^{2}} \exp \left(\frac{m^{2}-x^{2}}{2 \sigma^{2}}\right)\right)\left(p b \exp \left(\frac{m^{2}-x^{2}}{2 \sigma^{2}}\right)\left(1-\frac{b p x}{\sigma^{2}} \exp \left(\frac{m^{2}-x^{2}}{2 \sigma^{2}}\right)\right)+m-x\right)}{\left(1-\frac{b p m}{\sigma^{2}} \exp \left(\frac{m^{2}-x^{2}}{2 \sigma^{2}}\right)\right)^{3}}
$$

As seen before, all elements of the fraction are positive, and therefore $\frac{\partial^{2} m}{\partial x \partial p}>0$. Furthermore $\frac{\partial^{2} m}{\partial x \partial q}$ has the same sign as $\frac{\partial^{2} m}{\partial x \partial p}$.

End of Proof of Lemma 6.

Proposition 4 characterises an equilibrium A Perfect Bayesian Equilibrium requires the strategies of both players to maximise their expected utility, and the beliefs of the investor to be formed according to Bayesian rule whenever possible. These requirements are captured in our model by equations (2), (3) and (4). Our aim is therefore to show that our equilibrium satisfies these conditions and is feasible.

Note first that (see the proof of Proposition 3) the equilibrium action function $a(m)$ can be increasing in an interval $\left[m_{1}, m_{2}\right]$ only if all the messages in this interval are produced using pure strategies. It follows then that the increasing part of any equilibrium must satisfy (5). From Proposition 3 we also know that when $x$ is high enough, no message satisfies (5). Consequently, $\frac{\partial E[x \mid m]}{\partial m}=0$ must hold above certain value of $x$, which, for the moment we call $x^{*}$. Imagine also for the moment that a responsive action function, $\frac{\partial E[x \mid m]}{\partial m}>0$, can hold below $x^{*}$. We term these two parts the responsive and the non-responsive parts of the equilibrium.

Note now that in the responsive part of any equilibrium, the message issued by the biased analyst must follow the message function $m^{1}(x)$ characterised in Lemma 6. The reason is as follows. We have seen that only two message functions, $m^{1}(x)$ and $m^{2}(x)$ are compatible with (5). Furthermore, $m^{1}(x)$ is bounded from above, and $m^{2}(x)$ is bounded from below. But $m^{2}(x)$ cannot be part of the equilibrium, because when the biased analyst observes $x>x^{*}$ he must issue a message higher than $m^{*}$ (in none of these cases (5)) would hold. We notice then that the equilibrium of Proposition 4 entails a strictly increasing action function $a(m)$ whenever this is possible (i.e. below the point $x^{*}$ ). But if this is an equilibrium the beliefs of the investor about the message strategy of the biased analyst must be correct, and $\mu^{-1}($. from (3) must be the inverse of $m^{1}($.$) . Furthermore, since the analyst reaches his$ bliss point in this responsive part, it must be that $a=\mu^{-1}(m)+b=\left[m^{1}\right]^{-1}(m)+b$ whenever $m \leq m^{*}$. It is immediate to see that Subparts 2.a and 2.b of Proposition 4 are the converse of Subparts 3.a and 3.b of Lemma 6. Therefore the action function in the responsive part of an equilibrium must be concave and have a negative cross derivative. Notice last that we can define $a^{*}=a\left(m^{*}\right)$. 
Consider now the non-responsive part of the equilibrium. The action must be "flat" $a=a^{*} \forall m>m^{*}$. Messages above $m^{*}$ are issued by an honest analyst if he observes $x>m^{*}$ and by a biased type if he observes $x>x^{*}$. In the non-responsive section the action taken by the investor must be equal to the expected state given that the analyst has issued a message above $m^{*}$.

$$
\begin{aligned}
& a^{*}=P\left[\text { Honest } \mid m>m^{*}\right] * E[ \\
& \left.\quad x \mid m>m^{*}, \text { Honest }\right] \\
& +P\left[\text { Biased } \mid m>m^{*}\right] * E\left[x \mid m>m^{*}, \text { Biased }\right] \\
& a^{*}=\frac{\int_{m^{*}}^{\infty} \phi(x) d x * \int_{m^{*}}^{\infty} x \phi(x) d x+\int_{x^{*}}^{\infty} \phi(x) d x * \int_{x^{*}}^{\infty} x \phi(x) d x}{\int_{m^{*}}^{\infty} \phi(x) d x+\int_{x^{*}}^{\infty} \phi(x) d x}
\end{aligned}
$$

Rearranging (18) it is easy to find equation (6) that describes the value of the "flat" action taken in the non-responsive part of the equilibrium. Part 3a of Proposition 4 is therefore proved. Part $3 \mathrm{~b}$ derives directly from (2).

Lastly, we need to ensure that the equilibrium is continuous. The responsive part is continuous, as shown in Lemma 6 and in Part 2 of Proposition 4. The non-responsive part is flat, and therefore continuous. The last condition for the equilibrium to be continuous is that the action cannot "jump" at the point $x^{*}$. (6) capture this condition and determines jointly with (5) the point $\left(x^{*}, m^{*}\right)$.

Other (less responsive) equilibria In this subsection we find the other continuous equilibria of this game, and show that they are less responsive than the one in Proposition 4.

It is immediate to see that there can be an equilibrium where $a=E[x]=0$ and $m$ solves $(1-q) m \phi(m)+q \int x v(m \mid x) \phi(x) d x=0 \forall m$. Because in this equilibrium the action does not vary with the message, it is clearly less responsive that the one identified in Proposition 4.

Note next that an equilibrium where the action function is increasing in two intervals $\left[m_{1}, m_{2}\right]$ and $\left[m_{3}, m_{4}\right]$ but flat in the interval $\left[m_{2}, m_{3}\right]$, where $m_{1}<m_{2}<$ $m_{3}<m_{4}$, does not exist. The reason is the following. If the action function is flat between $m_{2}$ and $m_{3}$, then $a\left(m_{2}\right)=a\left(m_{3}\right)$. If the action function is increasing in the intervals $\left[m_{1}, m_{2}\right]$ and $\left[m_{3}, m_{4}\right]$, then from (4) it must be that the biased analyst is reaching his bliss point both when he announces $m_{2}$ and when he announces $m_{3}$. This is only possible if either $a\left(m_{2}\right)<a\left(m_{3}\right)$ which is an obvious contradiction, or $m_{2}$ and $m_{3}$ are both sent when the biased analyst observes the same $x$. But we know from Lemma 6 that the implicit function of $\mathrm{m}$ on $\mathrm{x}$ determined by $F(m, x)=0$ is uniquely determined, which creates a contradiction.

The only possibility left is now for an equilibrium with an increasing section in the middle of the message space and two flat sections on the lower and upper extremes. Lastly, note that an equilibrium is possible where: 
1. The action function is strictly increasing in the interval $\left[m^{* *}, m^{*}\right]$ and it is characterised by Subpart 2 of Proposition 4.

2. The action is flat to the right of $m^{*}$ with $a^{*}$ determined by (6) and (7) holding for any $m>m^{*}$.

3. The action is flat to the left of $m^{* *}$, with $a^{* *}$ characterised by:

$$
a^{* *}=\frac{q \phi\left(x^{* *}\right)+(1-q) \phi\left(m^{* *}\right)}{q \Phi\left(x^{* *}\right)+(1-q) \Phi\left(m^{* *}\right)}
$$

and the condition below holding for any $m<m^{* *}$ :

$$
\frac{(1-q) m \phi(m)+q \int_{-\infty}^{m^{* *}} x v(m \mid x) \phi(x) d x}{(1-q) \phi(m)+q \int_{-\infty}^{m^{* *}} v(m \mid x) \phi(x) d x}=a^{* *}
$$

4. An analyst that observes $x^{* *}$ is indifferent between the responsive and the nonresponsive part of the equilibrium:

$$
a^{* *}=\frac{q \phi\left(x^{* *}\right) x^{* *}+(1-q) \phi\left(m^{* *}\right) m^{* *}}{q \phi\left(x^{* *}\right)+(1-q) \phi\left(m^{* *}\right)}
$$

and, similarly, (8) holds for $x^{*}$.

Figure $\mathrm{F}$ shows the shape of this equilibrium. It is immediate to realise that it is identical to the most responsive equilibrium except for an extra flat part to the left of the message $m^{* *}$. The conclusion that this is a less responsive equilibrium is therefore obvious.

\section{End of Proposition 4.}

\section{R eferences}

[1] Abarbanell, Jeffery, and Reuven Lehavy, 2002 "Biased Forecasts or Biased Earnings? The Role of Reported Earnings in Explaining Apparent Bias and Over/Underreaction in Analysts' Earnings Forecasts" Unpublished Manuscript.

[2] Abarbanell, Jeffery, and Reuven Lehavy, 2000 "Differences in Commercial Database Reported Earnings: Implications for Inferences Concerning Analyst Forecast Rationality, the Association between Prices and Earnings, and Firm Reporting Discretion", Unpublished Manuscript.

[3] Austen-Smith, David 1990 "Information Transmission in Debate", American Journal of Political Science, 34:124-152. 
[4] Avery, Christopher and Margaret Meyer 2003 "Designing Hiring and Promotion Procedures when Evaluators are Biased" Unpublished Manuscript.

[5] Banerjee, Abhijit, 1992 "A Simple Model of Herd Behaviour," Quarterly Journal of Economics, 107: 797-817.

[6] Badrinath, S.G. and Sunil Wahal, 2002 "Momentum Trading by Institutions" Journal of Finance, 57:2449-2478.

[7] Benabou, Ronald and Guy Laroque, 1992 "Using Privileged Information to Manipulate Markets: Insiders, Gurus and Credibility", Quarterly Journal of Economics, 107: 921-958.

[8] Bikhchandani, Sushil, David Hirshleifer and Ivo Welch, 1992 "A Theory of Fads, Fashion, Custom and Cultural Change as Informational Cascades," Journal of Political Economiy, 100:992-1026.

[9] Boni, Leslie and Kent Womack, 2002 "Wall-Street's Credibility Problem: Misaligned Incentives and Dubious Fixes?" Wharton Financial Institutions Center Working Paper.

[10] Boni, Leslie and Kent Womack, 2002 "Solving the Sell-Side Research Problem: Insights from Buy-Side Professionals" Unpublished Manuscript.

[11] Brown, Lawrence, 1998 "Managerial Behaviour and the Bias in Analysts' Earnings Forecasts", Unpublished Manuscript.

[12] Chen, Qi and Wei Jiang, 2003 "Analysts' Weighting of Private and Public Information", Unpublished Manuscript.

[13] Crawford, Vincent, 2002 "Lying for Strategic Advantage: Rational and Boundedly Rational Misrepresentation of Intentions", Unpublished Manuscript.

[14] Crawford, Vincent and Joel Sobel, 1982 "Strategic Information Transmission", Econometrica, 50(6):1431-1452.

[15] Dechow, Patricia, Amy Hutton and Richard Sloan, 1998 "The Relation between Analysts' Forecasts of Long-Term Earnings Growth and Stock Price Performance Following Equity Offerings" Unpublished Manuscript.

[16] De Garidel-Thoron, Thomas, and Marco Ottaviani, 2000 "The Economics of Advice", Unpublished Manuscript.

[17] Dessein, Wouter, 2002 "Authority and Communication in Organizations", Review of Economic Studies, 69. 
[18] Francis, Jennifer and Donna Philbrick, 1993 " Analysts' Decisions as Products of a Multi-Task Environment" Journal of Accounting Research, 31:216-230.

[19] Francis, Jennifer and Leonard Soffer, 1997 "The Relative Informativeness of Analysts' Stock Recommendations and Earnings Forecasts Revisions" Journal of Accounting Research, 35:193-211

[20] Francis, Jennifer and Richard Willis, 2001 "An Alternative Test for Self-Selection in Analysts' Forecasts" Unpublished Manuscript.

[21] Gilligan, Thomas and Keith Krehbiel, 1989 "Asymmetric Information and Legislative Rules with a Heterogeneous Committee", American Journal of Political Science, 33:459-490.

[22] Gilligan, Thomas and Keith Krehbiel, 1989 "Organization of Informative Committees by a Rational Legislature", American Journal of Political Science, $34: 531-564$.

[23] Gu, Zhaoyang and Joanna Wu, 2001 "Earnings Skewness and Analysts Forecasts Bias", Unpublished Manuscript.

[24] Henriques, Diana 2000 "News in the Age of Money", Columbia Journalism Review, November/December Issue

[25] Khaneman, Daniel and Dan Lovallo, 1993 "Timid Choices and Bold Forecasts: A Cognitive Perspective on Risk Taking", Management Science, 39: 17-31.

[26] Keane, Michael and David Runkle, 1998 "Are Financial Analysts' Forecasts of Corporate Profits Rational?", Journal of Political Economy, 106: 768-805.

[27] Krishna, Vijay and John Morgan, 2001 "Asymmetric Information and Legislative Rules: Some Amendments", American Political Science Review, 95:435-452.

[28] Krigman, Laurie, Wayne Shaw and Kent Womack, 2001 "Why do firms switch underwriters?," Journal of Financial Economics, 60: 245-284

[29] Lim, Terence, 2001. "Rationality and Analysts' Forecast Bias," Journal of Finance, 56: 369-385.

[30] Lin, Hsiou-wei and Maureen McNichols, 1998 "Underwriting Relationships, Analysts' Earnings Forecasts and Investment Recommendations", Journal of Accounting and Economics, 25:101-127.

[31] McNichols, Maureen and Patricia O'Brien, 1997"Self-Selection and Analyst Coverage" Journal of Accounting Research, 35:167-199 
[32] Michaely, Roni and Kent Womack, 1999. "Conflict of interest and the credibility of underwriter analyst recommendations," Review of Financial Studies, 12: 653686.

[33] Morgan, John and Phillip Stocken, 2003 "An Analysis of Stock Recommendations", Rand Journal of Economics, 34: 183-203.

[34] Prendergast, Canice and Lars Stole, 1996 "Impetuous Youngsters and Jaded OldTimers: Acquiring a Reputation for Learning," Journal of Political Economy, 104: $1105-1034$.

[35] Ottaviani, Marco and Peter Sorensen, 2002, "The Strategy of Professional Forecasting", Unpublished Manuscript.

[36] Ottaviani, Marco and Francesco Squintani, 2002 "Non-Fully Strategic Information Transmission", Unpublished Manuscript.

[37] Scharfstein, David and Jeremy Stein, 1990 "Herd Behaviour and Investment," American Economic Review, 80: 465-479.

[38] Sobel, Joel, 1985 "A Theory of Credibility," Review of Economic Studies, 52: 557-573.

[39] The Economist Magazine, April 292003.

[40] Unger, Laura (US Securities and Exchange Commission Acting Chairman), July 312001 "Testimony to Committee on Financial Services".

[41] Welch, Ivo, 2000 "Herding among Security Analysts", Journal of Financial Economics, 58: 369-396.

[42] Zitzewitz, Eric, 2001a "Measuring Herding and Exaggeration by Equity Analysts and Other Opinion Sellers," Unpublished Manuscript.

[43] Zitzewitz, Eric, 2001b "Opinion-producing Agents: Career Concerns and Exaggeration," Unpublished Manuscript. 